NASA Technical Memorandum 105414

\title{
Semi-Empirical Model for Prediction of Unsteady Forces on an Airfoil With Application to Flutter
}

Aparajit J. Mahajan

University of Toledo

Toledo, Ohio

and

Krishna Rao V. Kaza

Lewis Research Center

Cleveland, Ohio 


\title{
SEMI-EMPIRICAL MODEL FOR PREDICTION OF UNSTEADY FORCES ON AN AIRFOIL WITH APPLICATION TO FLUTTER
}

\author{
Aparajit J. Mahajan ${ }^{*}$ \\ University of Toledo \\ Toledo, Ohio 43606 \\ and \\ Krishna Rao V. Kaza ${ }^{\dagger}$ \\ National Aeronautics and Space Administration \\ Lewis Research Center \\ Cleveland, Ohio 44135
}

\begin{abstract}
A semi-empirical model is described for predicting unsteady aerodynamic forces on arbitrary airfoils under mildly stalled and unstalled conditions. Aerodynamic forces are modeled using second order ordinary differential equations for lift and moment with airfoil motion as the input. This model is simultaneously integrated with structural dynamics equations to determine flutter characteristics for a two degrees-of-freedom system. Results for a number of cases are presented to demonstrate the suitability of this model to predict flutter. Comparison is made to the flutter characteristics determined by a Navier-Stokes solver and also the classical incompressible potential flow theory.
\end{abstract}

\footnotetext{
"NASA Resident Research Associate at Lewis Research Center. Previously with Duke University, Durham, NC 27706.

${ }^{\dagger}$ Deceased.
} 


\section{NOMENCLATURE}

\begin{tabular}{|c|c|}
\hline $\begin{array}{l}A_{0}, A_{1}, \text { etc } \\
a, a_{h}\end{array}$ & $\begin{array}{l}\text { coefficients in the model, Equations (1) and (10) } \\
\text { distance of elastic axis from the origin }\end{array}$ \\
\hline$a_{\infty}$ & speed of sound \\
\hline $\mathrm{B}_{1}$ & coefficient in the model, Equations (1) and (10) \\
\hline$b$ & semichord \\
\hline $\mathrm{C}_{\mathrm{h}}$ & damping coefficient in plunging \\
\hline $\mathrm{C}_{\mathrm{L}}$ & lift coefficient \\
\hline $\mathrm{C}_{\mathrm{M}}$ & moment coefficient about elastic axis \\
\hline $\mathrm{C}_{\alpha}$ & damping coefficient in pitching \\
\hline c & chord \\
\hline $\mathrm{h}$ & plunging (bending) displacement, positive downward \\
\hline $\mathrm{I}_{\alpha}$ & polar mass moment of inertia \\
\hline $\mathrm{K}_{\mathrm{h}}$ & plunging spring constant \\
\hline $\mathrm{K}_{\alpha}$ & pitching spring constant \\
\hline M & Mach number \\
\hline $\mathrm{m}$ & mass per unit length \\
\hline $\mathrm{Q}_{\mathrm{h}}$ & generalized force in plunging \\
\hline $\mathrm{Q}_{\alpha}$ & generalized force in pitching \\
\hline $\begin{array}{l}\operatorname{Re} \\
\mathrm{r}_{\alpha}\end{array}$ & $\begin{array}{l}\text { Reynolds number based on chord } \\
\text { radius of gyration about elastic axis }\end{array}$ \\
\hline S & static unbalance, $\mathrm{mbx}_{\alpha}$ \\
\hline $\mathrm{s}$ & nondimensional time, $\mathrm{Vt} / \mathrm{b}$ \\
\hline $\mathrm{t}$ & time \\
\hline $\mathrm{V}$ & resultant air velocity \\
\hline $\mathrm{V}_{\mathrm{F}}$ & flutter velocity \\
\hline $\mathrm{V}^{*}$ & nondimensional velocity $\mathrm{V} / \mathrm{b} \omega_{\alpha}$ \\
\hline $\mathrm{w}_{0.75 \mathrm{c}}$ & upwash at $3 / 4$ chord \\
\hline $\mathrm{w}$ & nondimensional upwash, $\mathrm{w}_{0.75 \mathrm{c}} / \mathrm{V}$ \\
\hline $\mathrm{x}_{\alpha}$ & distance between elastic axis and center of gravity \\
\hline
\end{tabular}




$\begin{array}{ll}\alpha_{\mathrm{S}} & \text { steady angle of attack } \\ \phi(\mathrm{s}) & \text { Wagner function } \\ \mu & \text { mass ratio } \\ \zeta_{\mathrm{A}} & \text { damping associated with fluid forces } \\ \zeta_{\mathrm{h}} & \text { critical damping coefficient in plunging } \\ \zeta_{\alpha} & \text { critical damping coefficient in pitching } \\ \rho & \text { air density } \\ \sigma & \text { time scale for superposition integral } \\ \tau & \text { nondimensional time, t a } / \mathrm{c} \\ \omega & \text { small amplitude harmonic oscillation frequency } \\ \omega_{\mathrm{A}} & \text { frequency associated with fluid forces } \\ \omega_{\mathrm{h}} & \text { uncoupled plunging frequency, } \sqrt{\mathrm{K}_{\mathrm{h}} / \mathrm{m}} \\ \omega_{\alpha} & \text { uncoupled pitching frequency, } \sqrt{\mathrm{K}_{\alpha} / \mathrm{I}}\end{array}$




\section{INTRODUCTION}

The aeroelastic response and flutter analysis of a helicopter rotor or an airplane wing or a turbomachine blade requires accurate information about aerodynamic forces under stalled and unstalled conditions. The theoretical approaches for prediction of aerodynamic forces including the effects of flow separation consist of the Navier-Stokes methods, the discrete vortex methods and the zonal methods. In the Navier-Stokes methods, the fundamental equations of fluid mechanics are solved by numerical techniques $1,2,3$. The discrete vortex methods solve for potential flow without the boundary layer $4,5,6$. The viscous nature of the flow is modeled by the generation and subsequent induced transport of discrete combined vortices. The manner and location of their generation is obtained empirically or through appropriate boundary layer calculations. The zonal methods model the flow as a combination of viscous, inviscid and transition zones 7,8 . In the numerical implementation of the model, these zones interact in an iterative manner. These theoretical models lack generality (due to various assumptions and restrictions of the formulation) and are computationally expensive. They are extremely difficult and expensive to incorporate into aeroelastic analysis codes.

For use in a standard aeroelastic analysis, various empirical and semi-empirical models have been developed to model the nonlinearity and phase changes in airfoil forces with respect to its motion. These methods are computationally fast and allow for various airfoil motions and flow conditions. These phenomenological models are not based on the first principles of fluid mechanics, but are obtained from understanding the physical relationship between the forces on airfoil and its motion. The different ways for modeling the nonlinearity in lift and moment are (1) corrected angle of attack, where the actual angle of attack is corrected to get the effective angle of attack ${ }^{9}$, which is a very popular approach in the aerospace industry, (2) time-delay, synthesis procedures, which involve curve-fitting experimental data with algebraic or transcendental functions ${ }^{10}$, and (3) ordinary differential equations, where the relationship between lift and angle of attack is described with an ordinary differential equation along with parameter identification from experimental data 11 .

Tran and Petot 11 originally proposed the idea of using ordinary differential equations to model the unsteady behavior of airfoil loads. The form of the ordinary differential equations was obtained by curve-fitting the experimental data for various airfoils. Substantial manual adjustment was needed to that model to predict accurately the airfoil loads. In the present work, a different semi-empirical model is developed to predict the lift and moment loads on an airfoil using an 
ordinary differential equation. The form of equation is motivated by physical considerations. It is assumed that the fluid lift force has the characteristics of a damped harmonic oscillator because of the fluid's inertia, dissipation and compliance. The airfoil motion is assumed to drive the fluid lift oscillator and the driving terms have nonlinear as well as linear components. The pitching moment is also represented using the same form of equation. The parameters in these equations are determined from comparison with airfoil load data for small amplitude oscillatory motion about a large steady angle of attack from a Navier-Stokes solver ${ }^{1}$. The model is then compared with the Navier-Stokes solver for large amplitude oscillatory motion of airfoil.

This model is then used to provide the aerodynamic loads to a two degrees-of-freedom structural dynamics model. The coupled second order ordinary differential equations are solved using an implicit linear multistep method with backward differentiation formula, also known as Gear's stiff method. The time response for a two degrees-of-freedom structural-fluid system using these equations is compared with those from the Navier-Stokes solver and the classical incompressible potential flow model.

\section{MATHEMATICAL AND NUMERICAL FORMULATION}

It is postulated that the lift coefficient of the airfoil, $\mathrm{C}_{\mathrm{L}}$, is related to the motion of the airfoil, its angle of attack, $\alpha$, through an ordinary differential equation of the following form:

$$
\ddot{\mathrm{C}}_{\mathrm{L}}+2 \zeta_{\mathrm{A}} \omega_{\mathrm{A}} \dot{\mathrm{C}}_{\mathrm{L}}+\omega_{\mathrm{A}}^{2} \mathrm{C}_{\mathrm{L}}=\mathrm{A}_{0}+\mathrm{A}_{1} \alpha+\mathrm{A}_{2} \alpha^{2}+\mathrm{A}_{3} \alpha^{3}+\mathrm{B}_{1}(\dot{\alpha}+\ddot{\alpha})
$$

where $\left({ }^{\circ}\right)$ denotes a time derivative.

This equation at present is postulated and not derived from first principles, e.g. from the Navier-Stokes equations. On the left hand side it is assumed that the fluid lift force has the characteristics of a damped harmonic oscillator because of the fluid's inertia, dissipation and compliance. On the right hand side, the body motion is assumed to drive the fluid lift oscillator and the driving terms have nonlinear as well as linear components in $\alpha, \dot{\alpha}$ and $\ddot{\alpha}$. The $\dot{\alpha}, \ddot{\alpha}$ and $\dot{C}_{L}$ terms allow for modeling the phase shifts between $C_{L}$ and $\alpha$. Once $\zeta_{A}, \omega_{A}, A_{1}, A_{2}, A_{3}, B_{1}$ are known, it is relatively simple to solve Equation (1) by analytical or numerical means for any arbitrary time dependent motion in combination with the structural dynamics equations. $\zeta_{\mathrm{A}}$ and $\omega_{\mathrm{A}}$ 
can be physically interpreted as a characteristic damping and frequency of the fluid. They are in general functions of $\alpha$.

To determine $\zeta_{A}, \omega_{A}, A_{1}, A_{2}, A_{3}$, and $B_{1}$ for a given airfoil at some Mach number and Reynolds number, a numerical or physical experiment is undertaken. First in a static experiment, Equation (1) simplifies to

$$
C_{L s}=\left(A_{0}+A_{1} \alpha_{s}+A_{2} \alpha_{s}^{2}+A_{3} \alpha_{s}^{3}\right) / \omega_{A}{ }^{2}
$$

where the subscript $\mathrm{s}$ refers to static or steady flow conditions. Note that $\omega_{\mathrm{A}}{ }^{2}$ appears for static conditions in Equation (2) due to the choice of harmonic oscillator representation in Equation (1). By curve-fitting the experimental data of $C_{L s}$ vs $\alpha_{S}$, the coefficients $A_{1} / \omega_{A}{ }^{2}, A_{2} / \omega_{A}{ }^{2}$ and $\mathrm{A}_{3} / \omega_{\mathrm{A}}{ }^{2}$ are determined.

Now the airfoil is oscillated about $\alpha_{\mathrm{s}}$, i.e.,

$$
\alpha(t)=\alpha_{s}+\hat{\alpha}(t)
$$

To determine $\zeta_{A}, \omega_{A}, B_{1}$, it is sufficient to consider $|\hat{\alpha}| \ll<\left|\alpha_{s}\right|$, i.e. only (infinitesimal) small oscillations about various static angles of attack need be considered to determine all the model parameters. In analogy to Equation (3), the lift coefficient can be written as,

$$
\mathrm{C}_{\mathrm{L}}=\mathrm{C}_{\mathrm{L}}+\widehat{\mathrm{C}}_{\mathrm{L}}
$$

For $|\hat{\alpha}| \ll\left|\alpha_{S}\right|$, then $\left|\hat{\mathrm{C}}_{L}\right| \ll\left|\mathrm{C}_{L_{S}}\right|$ and Equation (1) becomes

$$
\ddot{\widehat{C}}_{L}+2 \zeta_{A} \omega_{A} \dot{\widehat{C}}_{L}+\omega_{\AA}^{2} \widehat{\mathrm{C}}_{L}=\left(\mathrm{A}_{1}+2 \mathrm{~A}_{2} \alpha_{S}+3 \mathrm{~A}_{3} \alpha_{\sigma}^{2}\right) \hat{\alpha}+\mathrm{B}_{1}(\dot{\hat{\alpha}}+\ddot{\hat{\alpha}})
$$

Note that Equations (3), (4) and (5) should hold for both attached and separated flow for $\hat{\alpha}$ sufficiently small, i.e. one can still linearize about a steady, separated flow state. This linear relationship significantly simplifies the determination of $\zeta_{A}, \omega_{A}, B_{1}$. For small amplitude harmonic oscillations, substituing 


$$
\widehat{\alpha}=\bar{\alpha} e^{i \omega t}, \widehat{C}_{L}=\bar{C}_{L} e^{i \omega t}
$$

in Equation (5) gives,

$$
\bar{C}_{L}=\bar{\alpha}\left|\frac{\left(\mathrm{A}_{1}+2 \mathrm{~A}_{2} \alpha_{\mathrm{S}}+3 \mathrm{~A}_{3} \alpha_{\mathrm{S}}^{2}-\mathrm{B}_{1} \omega^{2}\right)^{2}+\left(\mathrm{B}_{1} \omega\right)^{2}}{\left(\omega_{\mathrm{A}}^{2}-\omega^{2}\right)^{2}+\left(2 \zeta_{\mathrm{A}} \omega_{\mathrm{A}} \omega\right)^{2}}\right|^{1 / 2} \mathrm{e}^{i \phi}
$$

where

$$
\phi=\tan ^{-1}\left[\frac{B_{1} \omega}{A_{1}+2 A_{2} \alpha_{S}+3 A_{3} \alpha_{S}^{2}-B_{1} \omega^{2}}\right]-\tan ^{-1}\left[\frac{2 \zeta_{A} \omega_{A} \omega}{\omega_{A}^{2}-\omega^{2}}\right]
$$

Considering the real part of $\widehat{\mathrm{C}}_{\mathrm{L}}$ Equation (6),

$$
\widehat{C}_{L}=\bar{\alpha}\left|\frac{\left(A_{1}+2 A_{2} \alpha_{S}+3 A_{3} \alpha_{S}^{2}-B_{1} \omega^{2}\right)^{2}+\left(B_{1} w\right)^{2}}{\left(\omega_{\AA}^{2}-\omega^{2}\right)^{2}+\left(2 \zeta_{A} \omega_{A} \omega\right)^{2}}\right|^{1 / 2} \cos (\omega t+\phi)
$$

$\zeta_{\mathrm{A}}, \omega_{\mathrm{A}}$ and $\mathrm{B}_{1}$ are determined by fitting Equation (9) to $\widehat{\mathrm{C}}_{\mathrm{L}}$ vs. $\widehat{\alpha}$ data from the Navier-Stokes solver. After determining $\zeta_{A}$, etc, Equation (1) can be used to determine $C_{L}(t)$ from a given $\alpha(t)$ even when the motion is large and transient (not just small and harmonic in time).

The moment coefficient of the airfoil, $\mathrm{C}_{\mathrm{M}}$, as a function of its angle of attack, $\alpha$, is also modeled in a similar manner as follows

$$
\ddot{\mathrm{C}}_{\mathrm{M}}+2 \zeta_{\mathrm{A}} \omega_{\mathrm{A}} \dot{\mathrm{C}}_{\mathrm{M}}+\omega_{\mathrm{A}}^{2} \mathrm{C}_{\mathrm{M}}=\mathrm{A}_{0}+\mathrm{A}_{1} \alpha+\mathrm{A}_{2} \alpha^{2}+\mathrm{A}_{3} \alpha^{3}+\mathrm{B}_{1}(\dot{\alpha}+\ddot{\alpha})
$$

The coefficients $\zeta_{A}, \omega_{A}, A_{1}, A_{2}, A_{3}$, and $B_{1}$ for $C_{M}$ are determined using the same procedure and the data from the Navier-Stokes solver. These coefficients may have different values for Equation(1) and Equation(10). On physical grounds, one may expect (hope) that $\zeta_{\mathrm{A}}$ and $\omega_{\mathrm{A}}$ will be similar for Equations (1) and (10). 
Note that the coefficients of the semi-empirical model were determined from a combination of theoretical/numerical and physical/experimental data for both attached and separated flow. The Sankar code was used for $\alpha<12^{\circ}$ to obtain both dynamic and static aerodynamic data. At higher $\alpha$ the Sankar code displayed oscillating lift even for a steady angle of attack and the results appeared sensitive to time step, artificial viscosity, grid spacing and other parameters. Therefore to determine the static coefficients, e.g. $A_{0}, A_{1}$, etc., for $12^{\circ}<\alpha<22^{\circ}$ the experimental data from McCroskey 12 were used. The available dynamic experimental data did not appear sufficient to independently assess the dynamic characteristics of the semi-empirical model and were not used.

It should be noted that according to the Sankar code, static separation begins at about $\alpha=10^{\circ}$ and at $\alpha=15^{\circ}$ the separation is still mild.

The Navier-Stokes solver was run on a CRAY XMP computer to generate small amplitude oscillation loops for lift and moment on a NACA 0012 airfoil at a Mach number of 0.3 and a Reynolds number of 4 million. The mean angle of attack was varied between $0^{\circ}$ and $12^{\circ}$ with the amplitude of oscillation being $0.1^{\circ}$. These values of Mach number, Reynolds number and angle of attack were selected, as the Navier-Stokes solver was validated over this range of values and gave physically meaningful results. Equation (9) was fitted for mean angles of attack between $0^{\circ}$ and $12^{\circ}$. Equation (2) was fitted to physical/experimental data for static angles of attack between $0^{\circ}$ and $15^{\circ}$ to incorporate the static stall behavior into the model. If a Navier-Stokes solver were available, that would generate reliable data in dynamic stall regime, the proposed model could be easily extended to predict dynamic stall behavior with reasonable accuracy.

The values of $\zeta_{A}, \omega_{A}, A_{1}, A_{2}, A_{3}$, and $B_{1}$ for $C_{L}$ and $C_{M}$ are given in Appendix 1 for a NACA 0012 airfoil at $M=0.3$ and $R e=4$ million. These parameters were determined using a nonlinear regression fitting procedure from the Statistical Analysis System (SAS) ${ }^{13}$. A comparison between this model and the Navier-Stokes solver for a large amplitude oscillation is shown in Figures 1 and 2. It can be seen that the model, which was fitted to small amplitude oscillation data, predicts large amplitude oscillation data accurately. These results are typical for the range of angles of attack considered in this paper.

To incorporate a plunging motion of the airfoil into the model, $\alpha$ is replaced by $(\alpha+\dot{h} / \mathrm{V})$ in Equations (1) and (10). This model is now integrated with structural dynamics equations for a 2 degrees-of-freedom system to analyze the flutter behavior of a NACA 0012 airfoil. 


\section{STRUCTURAL DYNAMICS MODEL}

A typical section model of an airfoil, as shown in Figure 3, is used for the flutter study. The typical section has two degrees-of-freedom, plunging (h) and pitching $(\alpha)$, positive as shown. The governing equations for this model are

$$
\begin{aligned}
& m \ddot{h}+S \ddot{\alpha}+C_{h} \dot{h}+K_{h} h=Q_{h} \\
& S \ddot{h}+I_{\alpha} \ddot{\alpha}+C_{\alpha} \dot{\alpha}+K_{\alpha} \alpha=Q_{\alpha}
\end{aligned}
$$

where $m$ is the mass, $S$ is static unbalance, $C_{h}, C_{\alpha}$ are structural damping parameters, $K_{h}$ and $K_{\alpha}$ are the pitching and plunging spring constants, $Q_{h}$ and $Q_{\alpha}$ are the generalized forces, and $\left(^{\circ}\right)$ is $\mathrm{d}(\mathrm{)}) / \mathrm{dt}$. Defining $\overline{\mathrm{h}}=\mathrm{h} / 2 \mathrm{~b}, \mathrm{x}_{\alpha}=\mathrm{S} / \mathrm{mb}, \mathrm{r}_{\alpha}^{2}=\mathrm{I}_{\alpha} / \mathrm{mb}^{2}, \omega_{\mathrm{h}}^{2}=\mathrm{K}_{\mathrm{h}} / \mathrm{m}, \omega_{\alpha}^{2}=K_{\alpha} / I_{\alpha}, C_{\mathrm{h}}=2 \zeta_{\mathrm{h}} \omega_{\mathrm{h}} \mathrm{m}$ and $C_{\alpha}=2 \zeta_{\alpha} \omega_{\alpha} I_{\alpha}$, where $b$ is the semi-chord, $I_{\alpha}$ is the mass moment of inertia about the elastic axis, $\omega_{h}$ and $\omega_{\alpha}$ are the uncoupled plunging and pitching frequencies, $\zeta_{h}$ and $\zeta_{\alpha}$ are the critical damping factors in bending and torsion, Equation (11) can be written as

$$
\begin{aligned}
& \ddot{\overline{\mathrm{h}}}+\left[\frac{\mathrm{x}_{\alpha}}{2}\right] \ddot{\alpha}+\left[2 \zeta_{\mathrm{h}} \omega_{\mathrm{h}}\right] \dot{\overline{\mathrm{h}}}+\left[\omega_{\mathrm{h}}^{2}\right] \overline{\mathrm{h}}=\frac{\mathrm{Qh}_{\mathrm{h}}}{2 \mathrm{mb}} \\
& {\left[\frac{\mathrm{x}_{\alpha}}{2}\right] \ddot{\overline{\mathrm{h}}}+\left[\frac{\mathrm{r}_{\alpha}}{2}\right]^{2} \ddot{\alpha}+\left[\frac{\zeta_{\alpha} \omega_{\alpha} \mathrm{r}_{\alpha}^{2}}{2}\right] \dot{\alpha}+\left[\frac{\omega_{\alpha} \mathrm{r}_{\alpha}}{2}\right]^{2} \alpha=\frac{\mathrm{Q}_{\alpha}}{4 \mathrm{mb}^{2}}}
\end{aligned}
$$

The generalized forces, $\mathrm{Q}_{h}$ and $\mathrm{Q}_{\alpha}$ are related to the lift and moment coefficients as follows:

$$
\begin{aligned}
& Q_{h}=-\frac{1}{2} \rho V^{2}(2 b) C_{L} \\
& Q_{\alpha}=\frac{1}{2} \rho V^{2}(2 b)^{2} C_{M}
\end{aligned}
$$

where $\mathrm{C}_{\mathrm{L}}$ is the lift coefficient, and $\mathrm{C}_{\mathrm{M}}$ is the moment coefficient about the axis of rotation (elastic axis), $V$ is the resultant air velocity and $\rho$ is air density. Defining, $\bar{t}=t a_{\infty} / 2 b$, and $V^{*}=V /\left(b \omega_{\alpha}\right)$, 
where $a_{\infty}$ is the speed of sound and substituting Equation (13) into Equation (12), the final aeroelastic equations can be written as

$$
\begin{aligned}
& \ddot{\overline{\mathrm{h}}}+\left[\frac{\mathrm{x}_{\alpha}}{2}\right] \ddot{\alpha}+\left[\frac{4 \zeta_{\mathrm{h}} \mathrm{M} \omega_{\mathrm{h}}}{\mathrm{V}^{*} \omega_{\alpha}}\right] \dot{\overline{\mathrm{h}}}+\left[\frac{2 \mathrm{M} \omega_{\mathrm{h}}}{\mathrm{V}^{*} \omega_{\alpha}}\right]^{2} \overline{\mathrm{h}}=-\frac{2 \mathrm{C}_{\mathrm{L}} \mathrm{M}^{2}}{\pi \mu} \\
& {\left[\frac{\mathrm{x}_{\alpha}}{2}\right] \ddot{\mathrm{h}}+\left[\frac{\mathrm{r}_{\alpha}}{2}\right]^{2} \ddot{\alpha}+\left[\frac{\zeta_{\alpha} \mathrm{r}_{\alpha}^{2} \mathrm{M}}{\mathrm{V}^{*}}\right] \dot{\alpha}+\left[\frac{\mathrm{Mr} \mathrm{r}_{\alpha}}{\mathrm{V}^{*}}\right]^{2} \alpha=\frac{\mathrm{C}_{\mathrm{M}} \mathrm{M}^{2}}{\pi \mu}}
\end{aligned}
$$

where $\left({ }^{\circ}\right)$ is now $\mathrm{d}\left(\mathrm{)} / \mathrm{dt}, \mathrm{M}=\mathrm{V} / \mathrm{a}_{\infty}\right.$ and $\mu$ is $\mathrm{m} / \pi \rho \mathrm{b}^{2}$. Equations (13) and (14) are used with any one of several aerodynamic theories.

Equations (1) and (10) for the semi-empirical aerodynamic theory are rewritten to include the effect of plunging displacement as follows:

$$
\begin{aligned}
& \ddot{\mathrm{C}}_{L}+2 \zeta_{A} \omega_{A} \dot{\mathrm{C}}_{L}+\omega_{A}^{2} \mathrm{C}_{L}=\mathrm{A}_{0}+\mathrm{A}_{1} \theta+\mathrm{A}_{2} \theta^{2}+\mathrm{A}_{3} \theta^{3}+\mathrm{B}_{1}(\dot{\theta}+\ddot{\theta}) \\
& \ddot{\mathrm{C}}_{M}+2 \zeta_{A} \omega_{A} \dot{\mathrm{C}}_{M}+\omega_{A}^{2} \mathrm{C}_{M}=\mathrm{A}_{0}+\mathrm{A}_{1} \theta+\mathrm{A}_{2} \theta^{2}+\mathrm{A}_{3} \theta^{3}+\mathrm{B}_{1}(\dot{\theta}+\ddot{\theta})
\end{aligned}
$$

where $\theta=\alpha+\dot{\mathrm{h}} / \mathrm{V}$. Substituting $\overline{\mathrm{h}}$ and $\overline{\mathrm{t}}$ for $\mathrm{h}$ and $\mathrm{t}$, and $\theta=\alpha+\dot{\mathrm{h}} / \mathrm{M}$. For simplicity, the bar on $\mathrm{h}$ and $t$ will be dropped for rest of the paper. Strictly speaking $\alpha$ should be replaced by $\alpha+\dot{h} / V$ Equation (1), but $\dot{\alpha}$ and $\ddot{\alpha}$ should be left alone . (However, for illustration purposes the present approach should suffice).

The Equations (14) and (15) form a system of four coupled, second-order ordinary differential equations. These equations are written as eight simultaneous first-order differential equations with corresponding initial conditions. These equations have widely varying time constants and can be described as a stiff system. The explicit methods, such as Runge-Kutta method, require a large number of small time steps in order to satisfy the accuracy requirement for the global error in a stiff system. So this initial value problem is solved using an implicit linear multistep method with a backward differentiation formula (Gear's method) from the IMSL library 14 . 


\section{THE NAVIER-STOKES MODEL}

The Navier-Stokes solver, that was used to generate data for fitting the semi-empirical model, was also used to provide aerodynamic loads for time-marching the solution to Equation (14). This code solves the full Navier-Stokes equations for 2-dimensional, unsteady, viscous flows in a body-fitted moving coordinate system. The code calculates $\mathrm{C}_{\mathrm{L}}$ and $\mathrm{C}_{\mathrm{M}}$ for initial values of $\alpha$ and $h$ for an airfoil. These values are then used to solve Equation (14) for new values of $\alpha$ and $h$ at the next time step. These new values of $\alpha$ and $h$ are then used by the code to calculate new $\mathrm{C}_{\mathrm{L}}$ and $\mathrm{C}_{\mathrm{M}}$ and so on. The fluid-structure interaction is thus analyzed in this explicit manner, even though the individual calculations to solve the Navier-Stokes equations or the structural dynamics equations are implicit. This procedure is described in detail, along with many examples, in 15,16 . The Navier-Stokes code should be reliable for fully attached and mildly separated flows.

\section{CLASSICAL INCOMPRESSIBLE POTENTIAL FLOW MODEL}

The aerodynamic loads input to Equation (14) was also calculated using the classical incompressible potential flow theory (linear aerodynamic theory) ${ }^{17}$. For an arbitrary time dependent motion, assuming the airfoil starts from rest at $t=0$,

$$
\operatorname{Lift}=\pi \rho b^{2}[\ddot{h}+V \dot{\alpha}-b a \ddot{\alpha}]-2 \pi \rho V b\left[w_{0.75 c}(0) \phi(s)+\int_{0}^{s} \frac{d_{0.75 c}(\sigma)}{d \sigma} \phi(s-\sigma) d \sigma\right]
$$

$$
\begin{aligned}
\text { Moment }= & \pi \rho b^{2}\left[b a \ddot{h}-\operatorname{Vb}\left(\frac{1}{2}-a\right) \dot{\alpha}-b^{2}\left(\frac{1}{8}+a^{2}\right) \ddot{\alpha}\right] \\
& -2 \pi \rho \operatorname{Vb}^{2}\left(\frac{1}{2}+a\right)\left[w_{0.75 c}(0) \phi(s)+\int_{0}^{s} \frac{d w_{0.75 c}(\sigma)}{d \sigma} \phi(s-\sigma) d \sigma\right]
\end{aligned}
$$

where $\phi(s)$ is Wagner function, $s=V t / b$ and $w_{0.75 c}=-V \alpha-\dot{h}-b\left(\frac{1}{2}-a\right) \dot{\alpha}$. Substituting $\bar{h}$ and $\bar{t}$ respectively for $h$ and $t$ and writing $C_{L}, C_{M}$ in terms of Lift and Moment 


$$
\begin{aligned}
& \mathrm{C}_{\mathrm{L}}=\pi\left[\frac{\ddot{\mathrm{h}}}{2 \mathrm{M}^{2}}+\frac{\dot{\alpha}}{2 \mathrm{M}}-\frac{\ddot{\mathrm{a}} \dot{\alpha}}{4 \mathrm{M}^{2}}\right]-2 \pi\left[\mathrm{w}(0) \phi(\mathrm{s})+\int_{0}^{\mathrm{s}} \frac{\mathrm{dw}}{\mathrm{d} \sigma} \phi(\mathrm{s}-\sigma) \mathrm{d} \sigma\right] \\
& \mathrm{C}_{\mathrm{M}}=\frac{\pi}{2}\left[\frac{\frac{\ddot{a}}{2 \mathrm{M}^{2}}}{2}-\frac{\left(\frac{1}{2}-\mathrm{a}\right) \dot{\alpha}}{2 \mathrm{M}}-\frac{\left(\frac{1}{8}+\mathrm{a}^{2}\right) \ddot{\alpha}}{4 \mathrm{M}^{2}}\right]-2 \pi\left(\frac{1}{2}+\mathrm{a}\right)\left[\mathrm{w}(0) \phi(\mathrm{s})+\int_{0}^{\mathrm{s}} \frac{\mathrm{dw}}{\mathrm{d} \sigma} \phi(\mathrm{s}-\sigma) \mathrm{d} \sigma\right]
\end{aligned}
$$

where $w=w_{0.75} / V=-\alpha-\frac{\dot{h}}{M}-\frac{1}{2}\left(\frac{1}{2}-a\right) \frac{\dot{\alpha}}{M}$ and $s=\frac{\bar{t}}{2 M}$. It should be noted that in above equations, Mach number appears due to the choice made for nondimensionalizing time and velocity. It has nothing to do with compressibility effects and the flow is still incompressible. Equations (14), (18) and (19) are solved in the same fashion as Equations (14) and (15) for the same initial conditions to analyze the fluid-structure interaction. This aerodynamic model should be reliable for attached flows at small angles of attack. It is used to provide a reference for the other aerodynamic models.

\section{RESULTS AND DISCUSSION}

The flutter behavior of a NACA 0012 airfoil at a Mach number of 0.3 was studied with the proposed semi-empirical model, the Navier-Stokes solver and the classical incompressible potential flow theory. The particular flow conditions and structural parameters were selected, so that a comparison can be made to some of the earlier flutter studies 15,16 .

For the flutter calculation using the semi-empirical model, first Equations (14) and (15) were solved with initial conditions as $\alpha=15^{\circ}, \mathrm{h}=0, \mathrm{C}_{\mathrm{L}}$ and $\mathrm{C}_{\mathrm{M}}$ as their steady state values at $15^{\circ}$ angle of attack, and the first derivatives with respect to nondimensional time as 0 . At these conditions, the airfoil is on the verge of stall. It was then released and was allowed to follow the motion dictated by the structural dynamics equations and the fluid dynamics model. The structural parameters used in this study are $a_{h}=-0.5, \omega_{h} / \omega_{\alpha}=0.2, x_{\alpha}=0.25, r_{\alpha}=0.5, \mu=100, \zeta_{h}$, $\zeta_{\alpha}=0$. Distances are nondimensionalized with respect to semi-chord (b), see Figure 3 for definitions. The dimensionless speed $\mathrm{V}^{*}$, was varied between 4 and 8 . The airfoil response to these two dimensionless speed values are shown in Figure 4 . It was found that at $V^{*}=4$, the airfoil returned to steady state following a period of damped oscillations. For the higher flutter speed case, $\mathrm{V}^{*}=8$, the airfoil oscillations grew rapidly with time, and flutter was triggered, as clearly 
seen in Figure 4. As discussed subsequently, for some $\mathrm{V}^{*}$ between 4 and 8 the motion was a limit cycle flutter.

The calculations shown above were repeated at lower angles of attack ( $\alpha$ between $0^{\circ}$ and $10^{\circ}$ ) and a similar flutter behavior was observed. The dimensionless speed $\mathrm{V}^{*}$ was varied between 4 and 8 . The airfoil response to these two dimensionless speed values at $5^{\circ}$ angle of attack are shown in Figure 5.

This was further analyzed by running the Navier-Stokes solver for these conditions and the same flutter behavior was observed. The starting point was the steady viscous flow over a NACA 0012 airfoil at 0.3 Mach number and 4 million Reynolds number. At $15^{\circ}$ angle of attack, the airfoil response are shown in Figure 6. Flutter can be seen at the higher speed and the damped oscillations at the lower speed. These calculations were repeated for $5^{\circ}$ angle of attack and the same flutter behavior was observed. These are shown in Figure 7.

The airfoil response were also calculated the classical potential flow model. The initial conditions for Equations (14), (18) and (19) were same as those for the semi-empirical model as explained earlier. At $5^{\circ}$ angle of attack, the results are shown in Figure 8. It can be seen that flutter occurs at higher speed and damped oscillations at lower speed. These calculations were repeated for higher angles of attack and a similar flutter phenomenon was observed. Of course, using the classical potential flow (linear) model, the flutter condition should be independent of initial conditions and that is found to be so.

For all three aerodynamic models, the damped and the flutter motions occurred at frequencies that roughly correspond to the natural frequency associated with the pitching motion. This suggests that the pitching mode is the most dominant mode in the flutter phenomenon considered here. In the present work, the Navier-Stokes solver was used to calculate the flutter response in fully attached flow (at $\alpha$ of $5^{\circ}$ ) and in mildly separated flow (at $\alpha$ of $15^{\circ}$ ). It was suggested in 16 , that a different type of airfoil response was observed in these cases, i.e. no flutter occurred in fully attached flow and flutter occurred in separated flow. In the present study, however, flutter occurred under both flow conditions for all three aerodynamic models. The semiempirical model for prediction of aerodynamic forces works well for fully attached flows and mildly separated flows, but was not extended to massively separated flows as no data were available for fitting in that region. The flutter behavior shown by the classical potential flow model, which assumes an inviscid flow and considers no stall effects, agrees reasonably well with that 
predicted by the other two methods. The agreement among these three different procedures further confirms this flutter as essentially conventional flutter and not stall flutter, perse.

Flutter boundary as a function of initial angle of attack is plotted in Figure 9. It can be observed that for angles less than $10^{\circ}$, a particular value of $\mathrm{V}_{\mathrm{F}}{ }^{*}$ gives neutrally stable oscillations. For $\mathrm{V}^{*}$ greater than this value, growing oscillations occur and for $\mathrm{V}^{*}$ less than this value, decaying oscillations occur. The flow over airfoil is fully attached for these initial angles of attack.

Note the velocity for onset of flutter decreases as angle of attack increases as intuition might suggest. However, at sufficiently large angle of attack, once flutter begins at some velocity it is a finite amplitude limit cycle oscillation until some larger velocity is exceeded when the oscillation then grows (exponentially) with time. For angles greater than $10^{\circ}$, neutrally stable, limit cycle oscillations occur over a range of values of $\mathrm{V}^{*}$ instead of one particular value. Below this range, decaying oscillations are seen and above this range, growing oscillations occur. These oscillations are shown in Figure 10. A limit cycle behavior in the phase plane is observed over a range of $\mathrm{V}^{*}$ as seen in Figure 11. The emergence of this limit cycle region coincides with the transition from fully attached flow to mildly separated flow over the airfoil. This behavior was also exhibited by the Navier-Stokes solver for similar initial conditions as shown in Figures 12 and 13.

It should be noted, however, that the range of $\mathrm{V}^{*}$ over which the limit cycle is observed is somewhat different for the two fluid dynamics models. Typically the difference is modest, of the order of $20 \%$ in flow velocity. For the semi-empirical fluid model, a limit cycle of finite amplitude is observed over the range of $\mathrm{V}^{*} \approx 5.25-6.75$. For the Navier-Stokes fluid model, a limit cycle was observed at $\mathrm{V}^{*}=4.75$, but not at $\mathrm{V}^{*} \leq 4$ or $\mathrm{V}^{*} \geq 5.5$. A comparison of results from the Navier-Stokes solver and the semi-empirical model for the maximum limit cycle amplitude is shown in Figure 14. The results are similar qualitatively although there are obvious quantitative differences.

Because of the substantial computational cost, only a limited number of results were obtained using the Navier-Stokes solver. The flutter calculation using the Navier-Stokes solver took about 6000 seconds of computer time on a CRAY-XMP. Whereas, the other two methods required 4-5 seconds of computer time for a similar calculation. This shows the considerable savings in computer time (and memory), that can be achieved by use of the semi-empirical model in a standard aeroelastic analysis. Unfortunately there are no available experimental flutter data to compare to the present results from either the semi-empirical model or the Navier-Stokes model at high angles of attack. Note that the flutter results obtained from classical, linear potential theory are 
included in the present discussion primarily as reference data. One would not expect the latter result to be meaningful at large angles of attack of course. However the classical aerodynamic theory has been experimentally validated for flutter at small angles of attack.

\section{CONCLUSIONS}

A system of ordinary differential equations can be used to model the aerodynamic forces on an airfoil for arbitrary motions. This semi-empirical model can be fitted for a variety of flow conditions including separated flows, provided experimental (physical or numerical) data exist for those conditions. This model then can be used with the structural dynamics equations to analyze flutter behavior of an airfoil in a standard aeroelastic analysis including conditions of mild flow separation. The savings in computer time and memory requirement are significant in comparison to the methods based directly on the Navier-Stokes equations.

An interesting phenomenon is observed, where the structural-fluid interaction shows a limit cycle behavior as a function of $\mathrm{V}^{*}$. For fully attached flows, this limit cycle behavior is seen for only a certain value of $\mathrm{V}^{*}$, whereas for mildly separated flows, it is seen over a range of $\mathrm{V}^{*}$. Further studies are being done to understand this phenomenon better.

At present, this semi-empirical aerodynamic model is postulated, but efforts are underway to demonstrate its deduction from the first principles of fluid mechanics.

\section{ACKNOWLEDGMENTS}

The authors would like to express their appreciation for many useful discussions with Professors Earl H. Dowell and Donald B. Bliss of Duke University. The first author was supported, in part, by NASA Lewis Research Center Grant NAG3-724. 


\section{REFERENCES}

(1) Sankar, N. L. and Tang, W., "Numerical Solution of Unsteady Viscous Flow Past Rotor Sections," AIAA Paper 85-0129, Jan. 1985.

(2) Shamroth, S.J., "Calculation of Steady and Unsteady Airfoil Flow Fields via the NavierStokes Equations," NASA CR 3899, 1985.

(3) Steger, J.L., "Implicit Finite Difference Simulation of Flow About Arbitrary Geometries," AIAA Journal, Vol.16, No.7, July 1978.

(4) Ham, N.D. and Garelick, M.S., "Dynamic Stall Considerations in Helicopter Rotors," $J$. Am. Helicopter Soc., Vol.13, No. 2, April 1968, pp. 49-55.

(5) Ono, K., Kuwahara, K. and Oshima, K., "Numerical Analysis of Dynamic Stall Phenomena of Oscillating Aerofoil by the Discrete Vortex Approximation," Lecture Notes in Physics, Vol.141, Springer Verlag, 1981. pp. 310-315.

(6) Katz, J., "A Discrete Vortex Method for the Nonsteady Separated Flow Over an Airfoil," J. Fluid Mech., Vol.102, Jan. 1981, pp. 315-328.

(7) Perumal, P.V.K. and Sisto, F., "Lift and Moment Prediction for an Oscillating Airfoil with a Moving Separation Point," J. Eng. Power, Vol.96, No.4, Oct. 1974, pp. 372-378.

(8) Chi, R.M., "Separated Flow Unsteady Aerodynamic Theory," J. Aircraft, Vol.22, No.11, Nov. 1985, pp. 956-964.

(9) Harris, F.D., Tarzanin, F.J., Jr. and Fisher, R.K., "Rotor High-Speed Performance; Theory vs Test," J. Am Helicopter Soc., Vol. 15, No. 3, 1970, pp. 35-44.

(10) Gangwani, S.T., "Synthesized Unsteady Airfoil Data Method for Prediction of Dynamic Stall and Unsteady Airloads," NASA CR 3672, 1983.

(11) Tran, C.T. and Petot, D., " Semi-Empirical Model for the Dynamic Stall of Airfoils in View of the Application to the Calculation of Responses of a Helicopter Blade in Forward Flight," Vertica, Vol.5, 1981, pp.35-53.

(12) McAlister, K., Pucci, S.L., McCroskey, W.J. and Carr, L.W., "An Experimental Study of Dynamic Stall of Advanced Airfoil Sections," Vol. 2, NASA TM 84245, Sept. 1982.

(13) SAS User's Guide, SAS Institute, Inc, Cary, North Carolina, 1985.

(14) User's Manual, Math Library, Version 10.0, IMSL, Houston, Texas, 1987.

(15) Reddy, T.S.R., Srivastava, R. and Kaza, K.R.V., "The Effects of Rotational Flow, Viscosity, Thickness, and Shape on Transonic Flutter Dip Phenomena," NASA TM 100811, April 1988.

(16) Wu, J.C., Kaza, K.R.V. and Sankar, L.N., "A Technique for the Prediction of Airfoil Flutter Characteristics in Separated Flow," J. Aircraft, Vol. 26, No. 2, 1989, pp. 168-176. 
(17) Dowell, E.H., Curtiss, H.C.,Jr., Scanlan, R.H. and Sisto, F., A Modern Course in Aeroelasticity, Second Edition, Kluwer Academic Publishers, The Netherlands, 1989.

\section{APPENDIX 1}

\section{PARAMETERS FOR THE SEMI-EMPIRICAL MODEL}

(NACA 0012 airfoil at $\mathrm{M}_{\infty}=0.3$ and $\mathrm{R}_{\mathrm{e}}=4$ million)

Parameters for Equation (1):

$\mathrm{A}_{0} / \omega_{\mathrm{A}}^{2}=0, \mathrm{~A}_{1} / \omega_{\mathrm{A}}^{2}=5.4878, \mathrm{~A}_{2} / \omega_{\mathrm{A}}^{2}=14.0997, \mathrm{~A} / \omega_{\mathrm{A}}^{2}=-55.198$.
$\zeta_{\mathrm{A}}=\zeta_{\mathrm{A} 0}+\zeta_{\mathrm{A} 1} \alpha+\zeta_{\mathrm{A} 2} \alpha^{2}, \zeta_{\mathrm{A} 0}=2.898, \zeta_{\mathrm{A} 1}=54.701, \zeta_{\mathrm{A} 2}=-291.0861$.
$\omega_{\mathrm{A}}=\omega_{\mathrm{A} 0}+\omega_{\mathrm{A} 1} \alpha+\omega_{\mathrm{A} 2} \alpha^{2}, \omega_{\mathrm{A} 0}=7.0293, \omega_{\mathrm{A} 1}=-52.212, \omega_{\mathrm{A} 2}=279.09$.
$\mathrm{B}_{\mathrm{A}}=\mathrm{B}_{\mathrm{A} 0}+\mathrm{B}_{\mathrm{A} 1} \alpha+\mathrm{B}_{\mathrm{A} 2} \alpha 2, \mathrm{~B}_{\mathrm{A} 0}=242.709, \mathrm{~B}_{\mathrm{A} 1}=415.509, \mathrm{~B}_{\mathrm{A} 2}=-2230.9$.

Parameters for Equation (10):

For $\alpha<10.0174^{\circ}$,

$\mathrm{A}_{0} / \omega_{\mathrm{A}}{ }^{2}=0, \mathrm{~A}_{1} / \omega_{\mathrm{A}}{ }^{2}=-0.01557, \mathrm{~A}_{2} / \omega_{\mathrm{A}}{ }^{2}=-0.0998, \mathrm{~A}_{3} / \omega_{\mathrm{A}}{ }^{2}=1.1753$.

For $10.0174^{\circ}<\alpha<13.5636^{\circ}$,

$\mathrm{A}_{0} / \omega_{\mathrm{A}}{ }^{2}=1.466, \mathrm{~A}_{1} / \omega_{\mathrm{A}}{ }^{2}=-22.585, \mathrm{~A}_{2} / \omega_{\mathrm{A}}{ }^{2}=115.66, \mathrm{~A}_{3} / \omega_{\mathrm{A}}{ }^{2}=-196.84$.

For $13.5636^{\circ}<\alpha$,

$\mathrm{A}_{0} / \omega_{\mathrm{A}}{ }^{2}=4.314, \mathrm{~A}_{1} / \omega_{\mathrm{A}}{ }^{2}=-41.328, \mathrm{~A}_{2} / \omega_{\mathrm{A}}{ }^{2}=129.49, \mathrm{~A}_{3} / \omega_{\mathrm{A}}{ }^{2}=-135.48$.

For all $\alpha$,

$\zeta_{\mathrm{A}}=\zeta_{\mathrm{A} 0}+\zeta_{\mathrm{A} 1} \alpha, \zeta_{\mathrm{A} 0}=3.4004, \zeta_{\mathrm{A} 1}=3.3174$

$\omega_{\mathrm{A}}=\omega_{\mathrm{A} 0}+\omega_{\mathrm{A} 1} \alpha, \omega_{\mathrm{A} 0}=10.1120, \omega_{\mathrm{A} 1}=-4.0498$.

$\mathrm{B}_{\mathrm{A}}=\mathrm{B}_{\mathrm{A} 0}+\mathrm{B}_{\mathrm{A} 1} \alpha, \mathrm{B}_{\mathrm{A} 0}=-71.87, \mathrm{~B}_{\mathrm{A} 1}=27.9352$. 


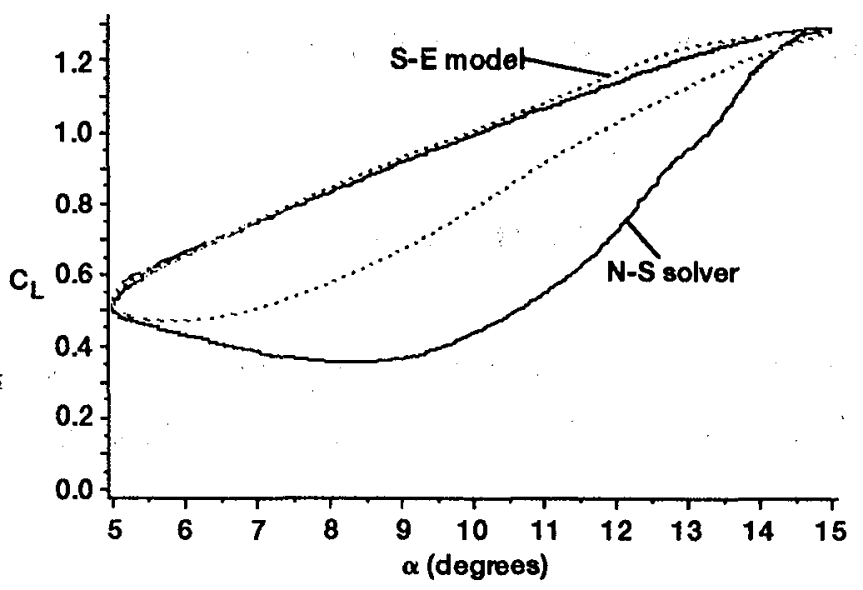

Figure 1.-Lift coefficient from semi-empirical model and Navier-Stokes solver (NACA 0012 airfoil, $\alpha=10^{\circ}-5^{\circ} \cos (\omega t)$, $M=0.3, R_{e}=4$ million).

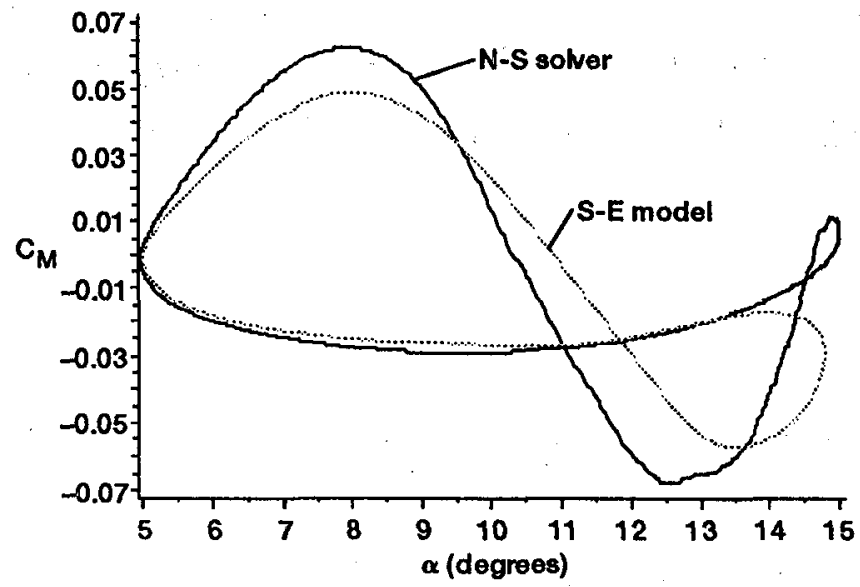

Figure 2.- Moment coefficient from semi-empirical model and Navier-Stokes solver (NACA 0012 aiffoil, $\alpha=10^{\circ}-5^{\circ} \cos (\omega t)$, $M=0.3, R e=4$ million).

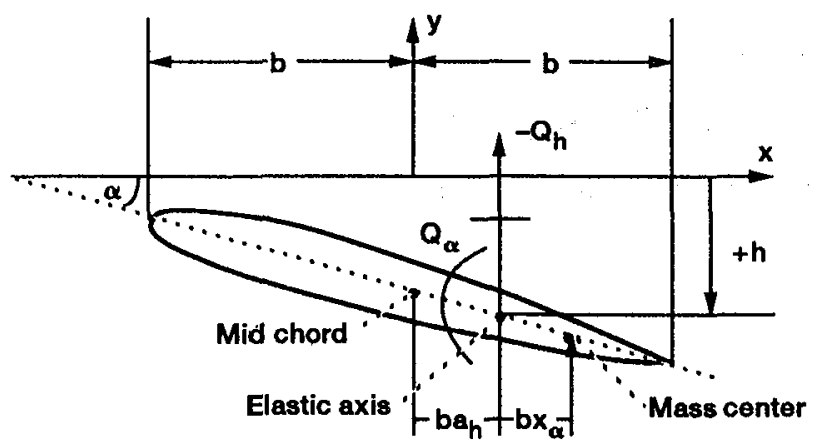

Figure 3.-Two degrees-of-freedom typical section model. 


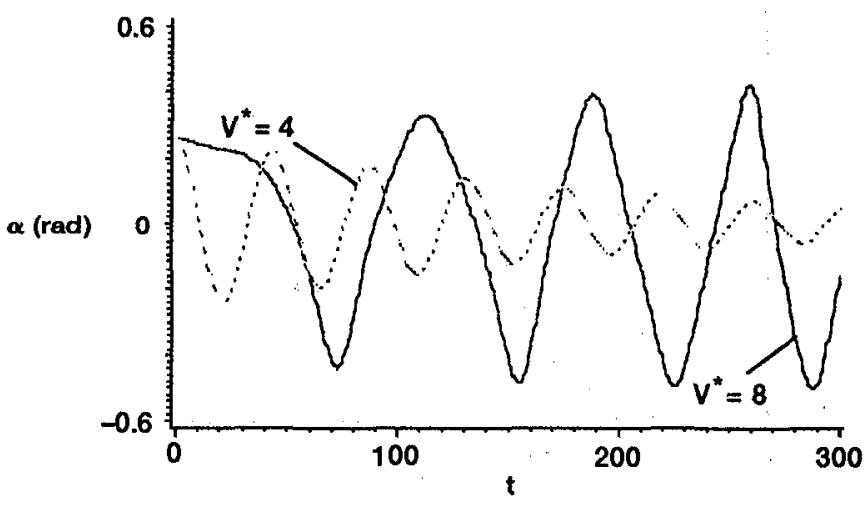

(a)

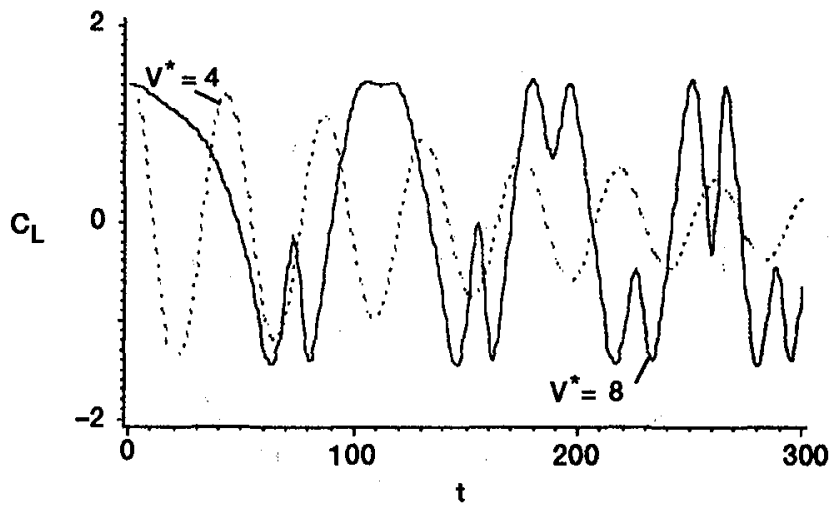

(c)

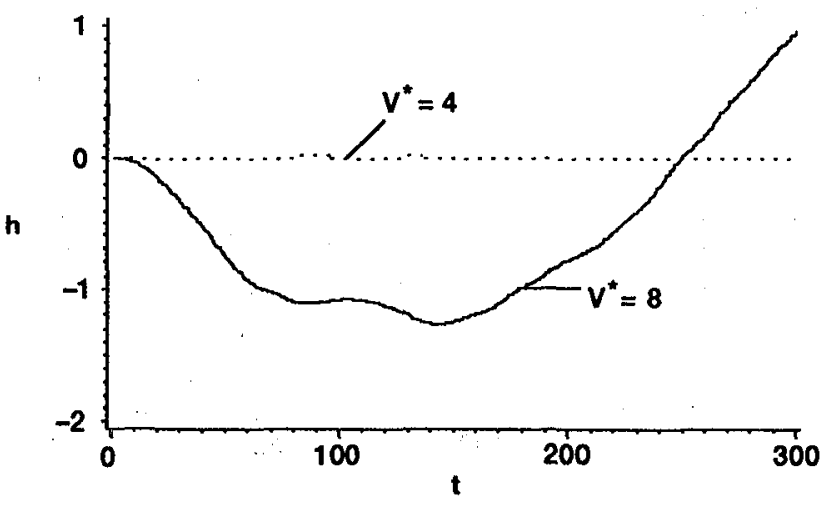

(b)

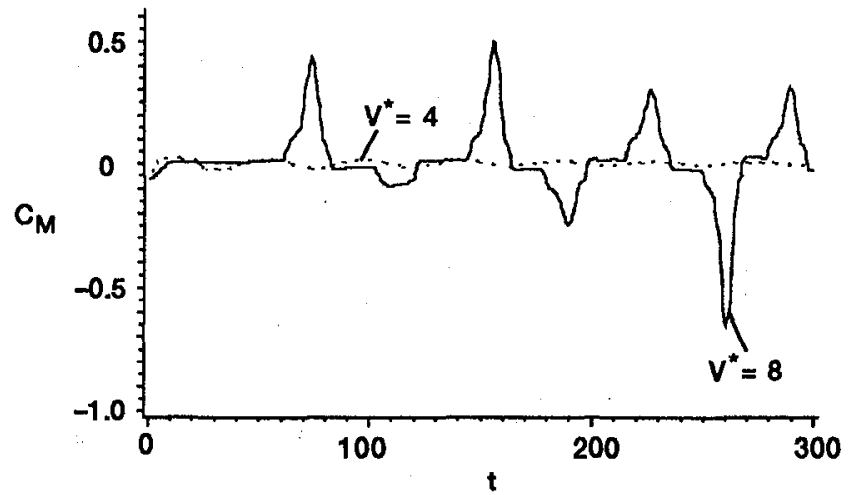

(d)

Figure 4.-Time response of a two degree-of-treedom solid-fluid system using the semi-empirical model (NACA 0012 airfoil, $M=0.3$, $R e=4$ million, initial angle of attack $=15^{\circ}$ ). 


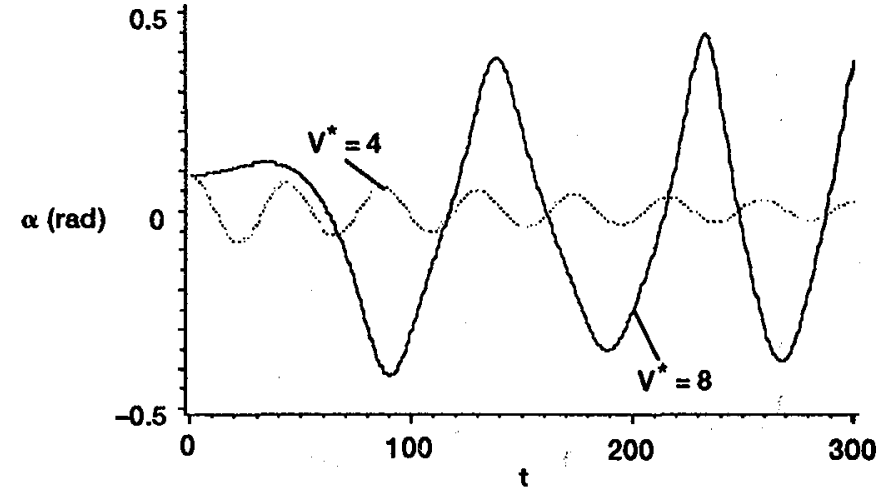

(a)

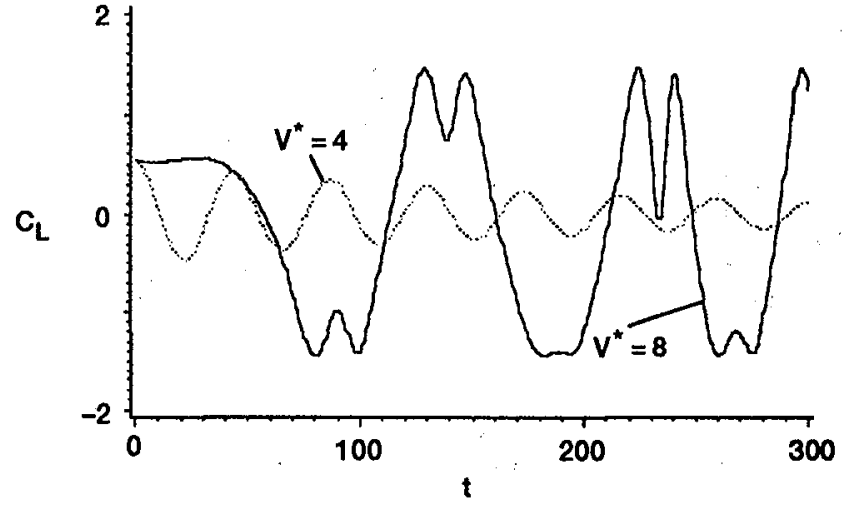

(c)

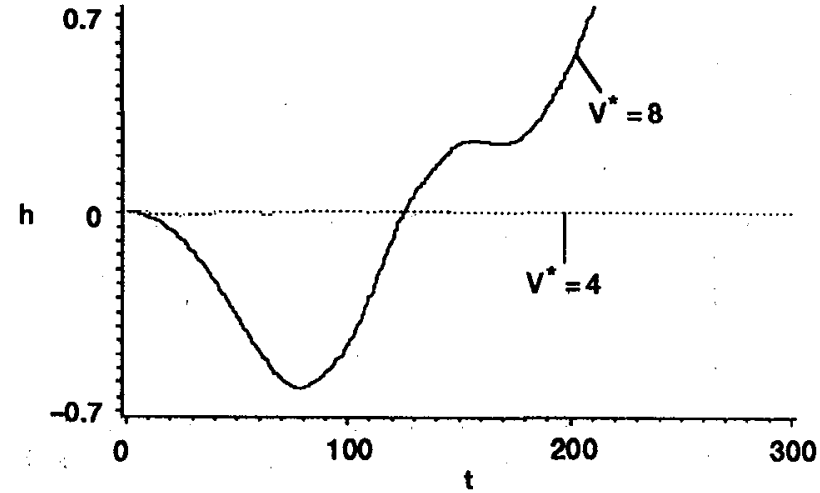

(b)

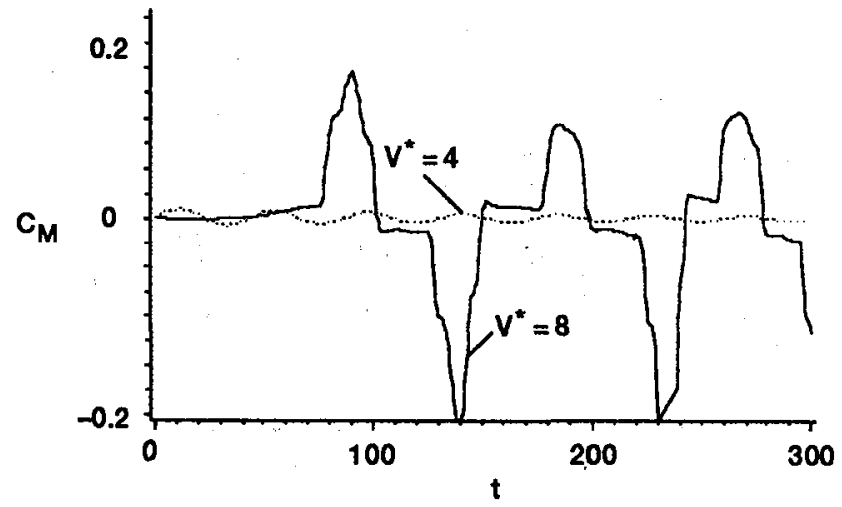

(d)

Figure 5. -Time response of a two degree-of-freedom solid-fluid system using the semi-empirical model (NACA 0012 airfoil, $M=0.3$, $\mathrm{Re}=4$ million, initial angle of attack $=5^{\circ}$ ). 


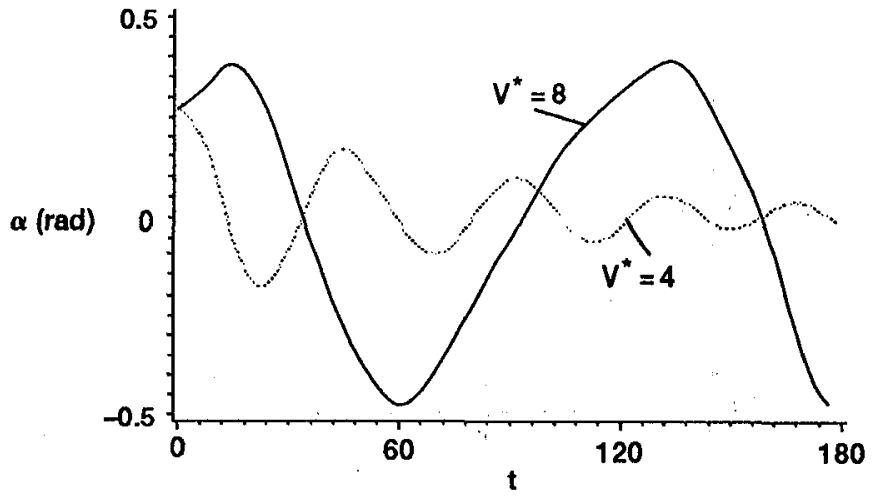

(a)

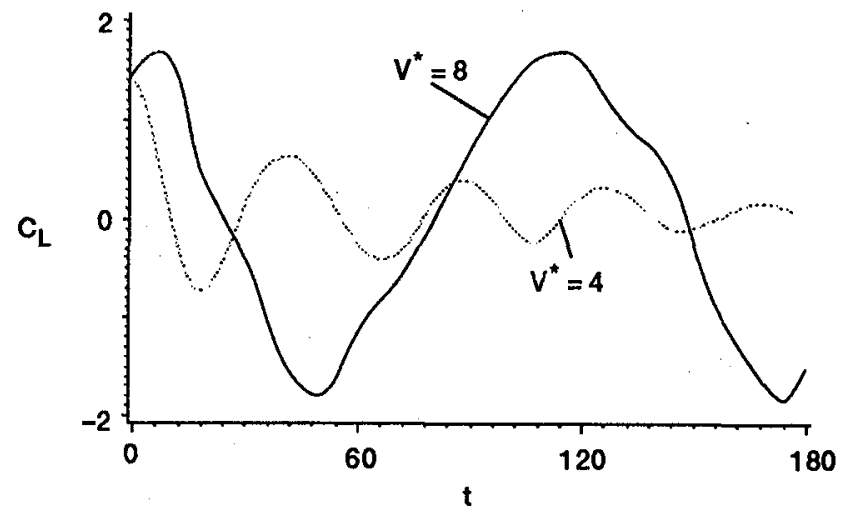

(c)

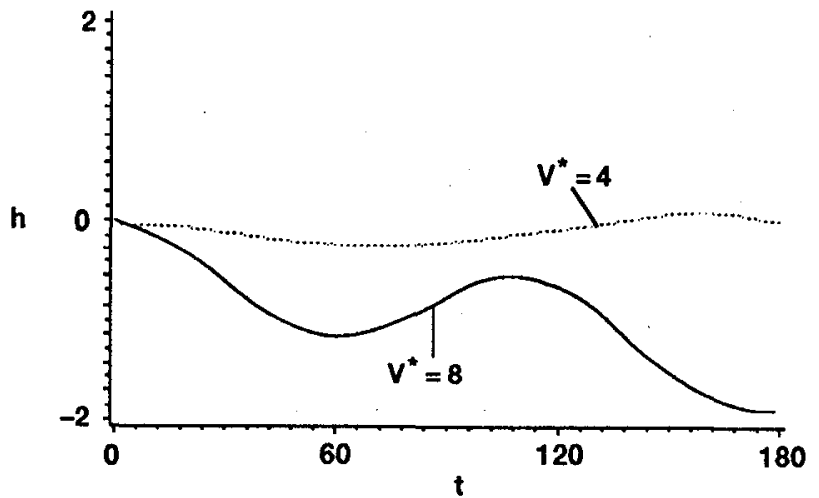

(b)

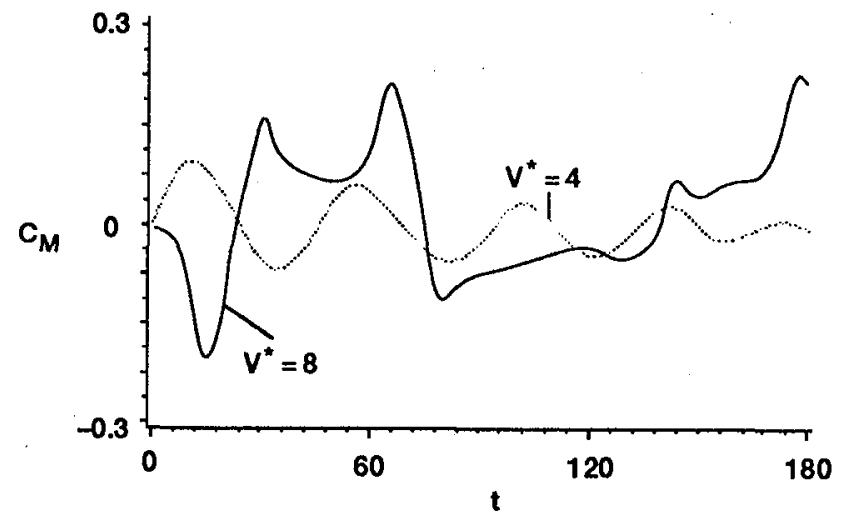

(d)

Figure 6.-Time response of a two degree-of-freedom solid-fluid system using the Navier-Stokes solver (NACA 0012 airfoil, M = 0.3 , $R e=4$ million, initial angle of attack $=15^{\circ}$ ). 


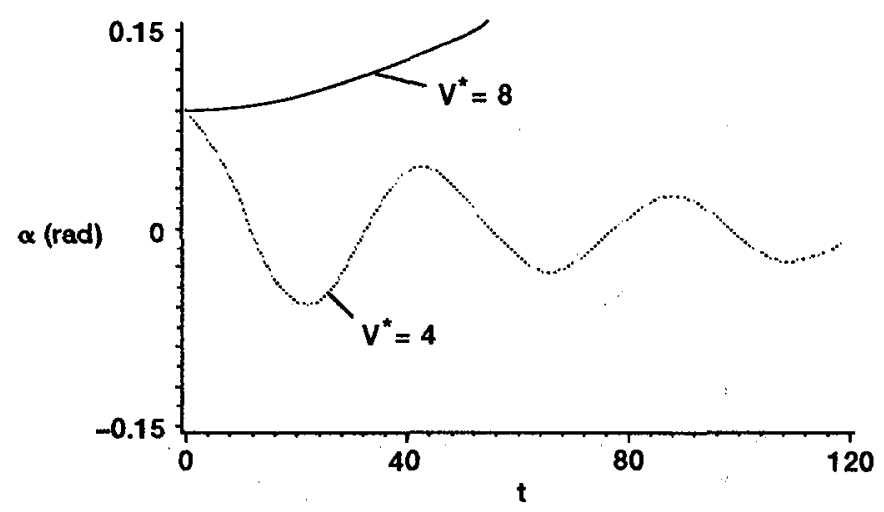

(a)

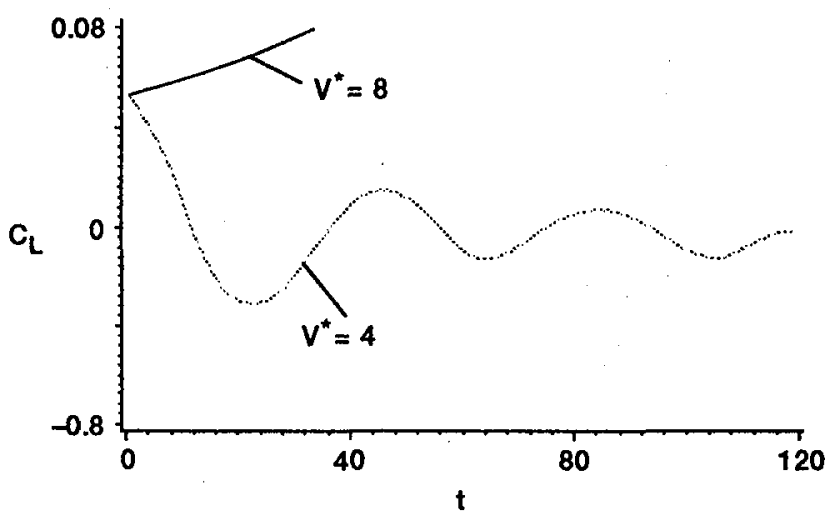

(c)

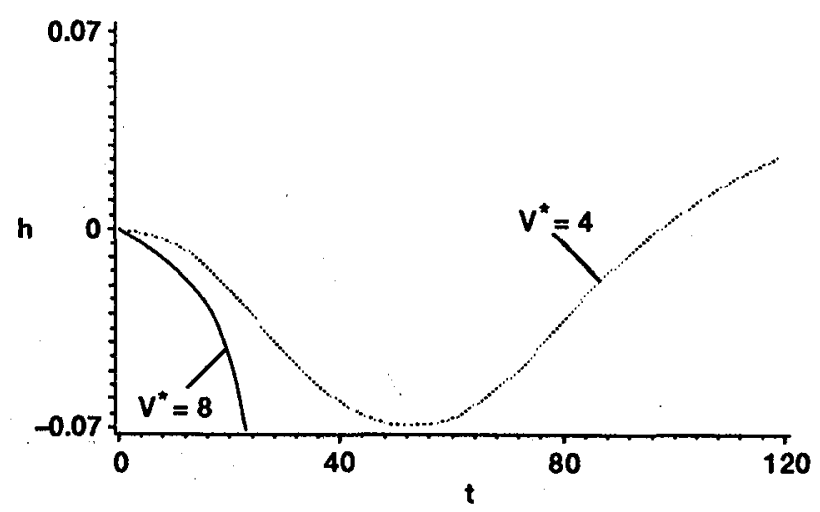

(b)

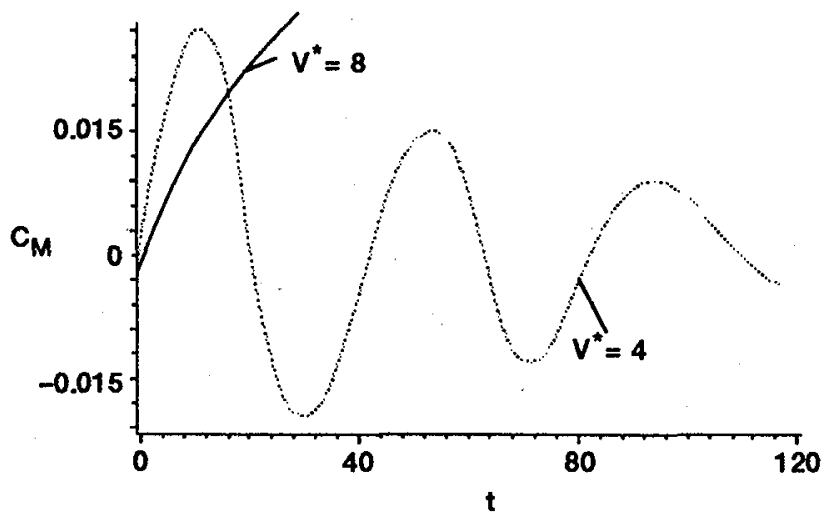

(d)

Figure 7.-Time response of a two degree-of-freedom solid-fluid system using the Navier-Stokes solver (NACA O012 airfoil, M = 0.3, $\mathrm{Re}=4$ million, initial angle of attack $=5^{\circ}$ ). 


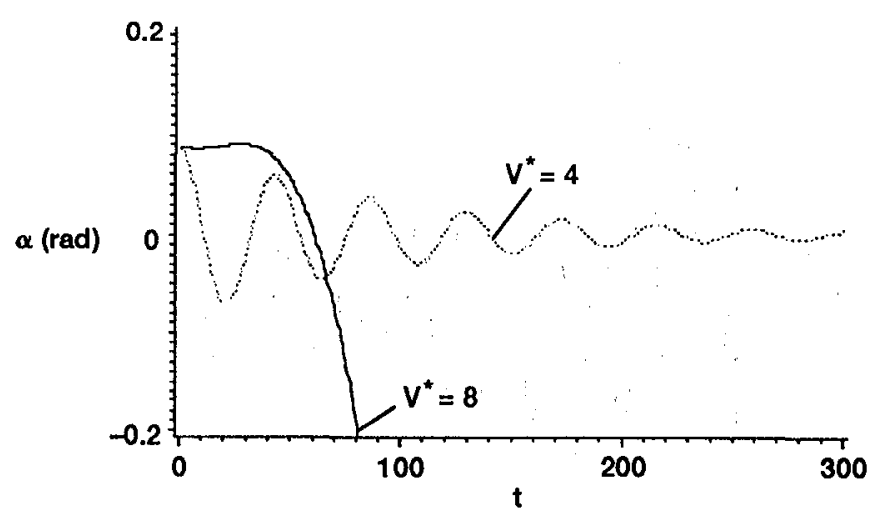

(a)

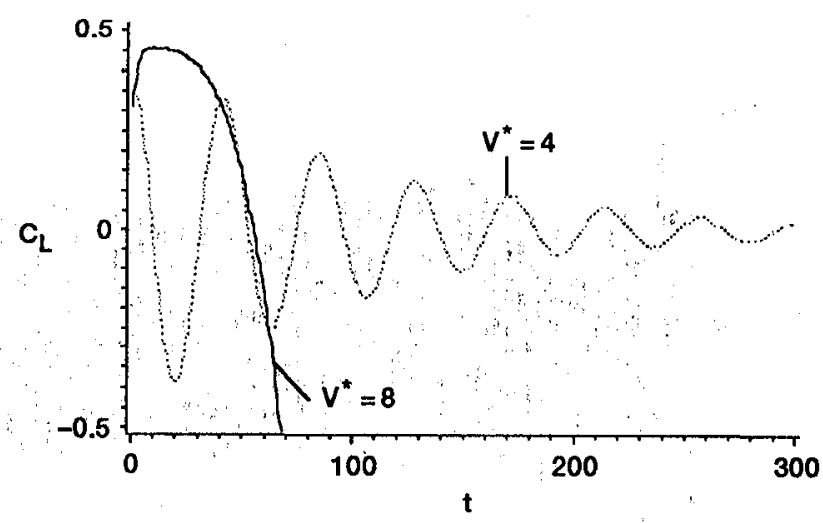

(c)

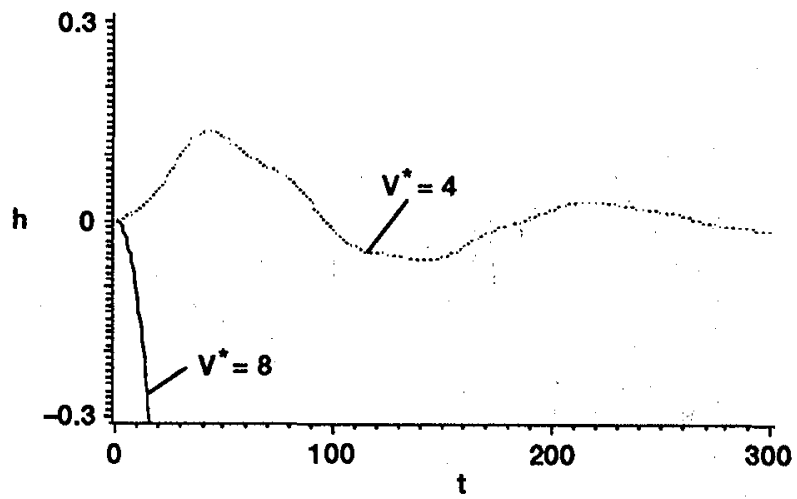

(b)

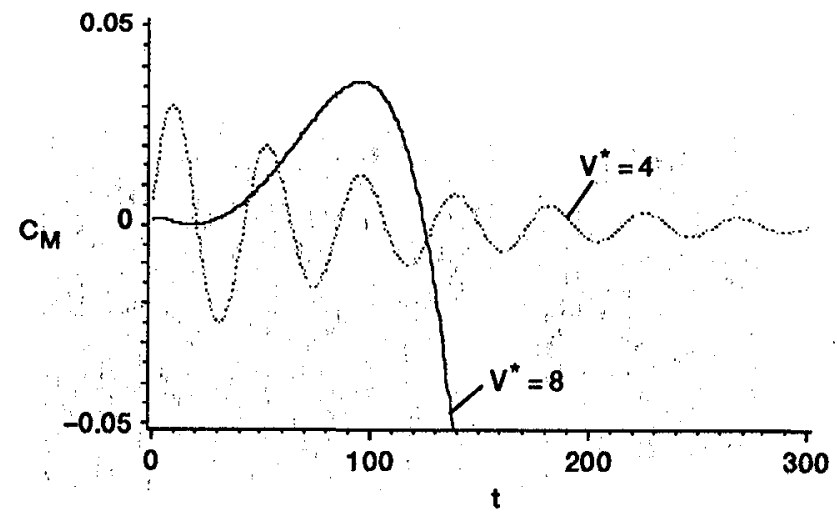

(d)

Figure 8. -Time response of a two degree-of-freedom solid-fluid system using the classical incompressible potential flow theory (NACA 0012 airfoil, $M=0,3, R e=4$ miltion, initial angle of attack $=5^{\circ}$ ).

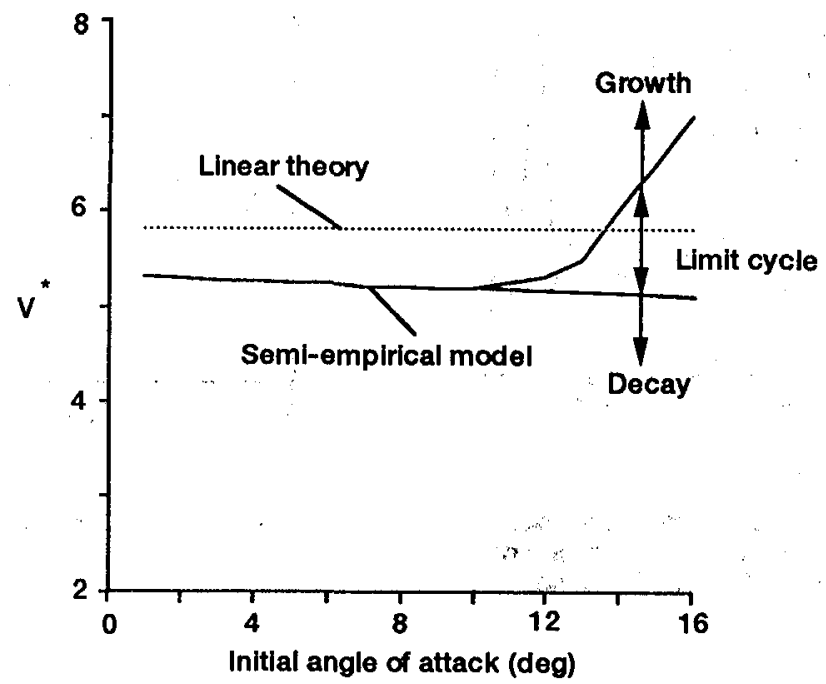

Figure 9.-Flutter boundary as a function of initial angle of attack. 


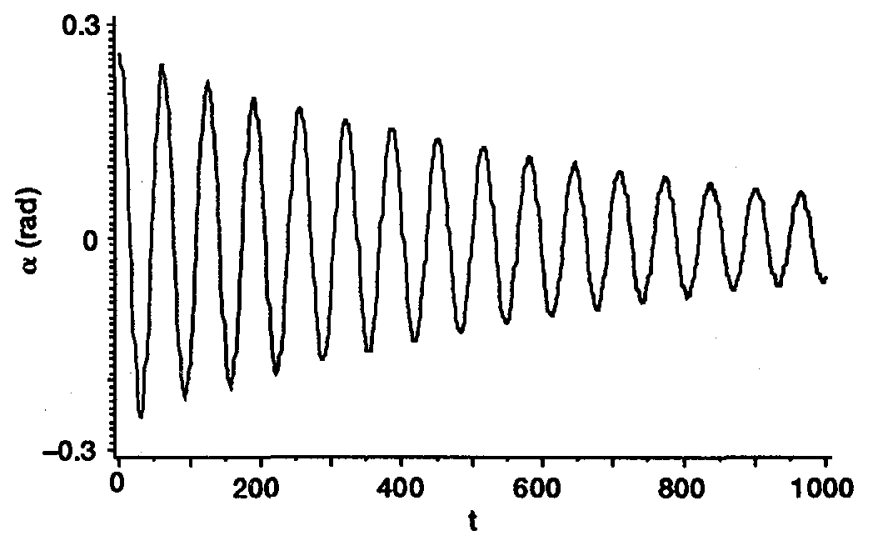

(a) $V^{*}=5.0$

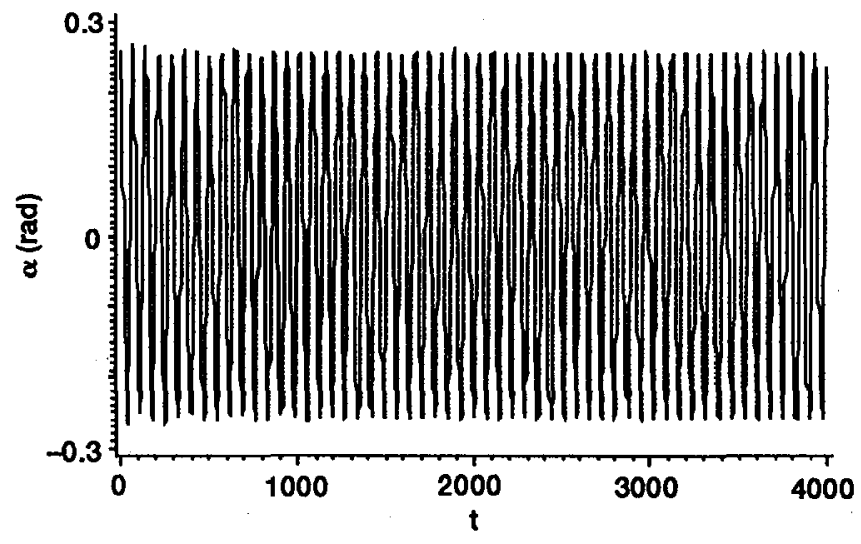

(b) $V^{\star}=5.5$

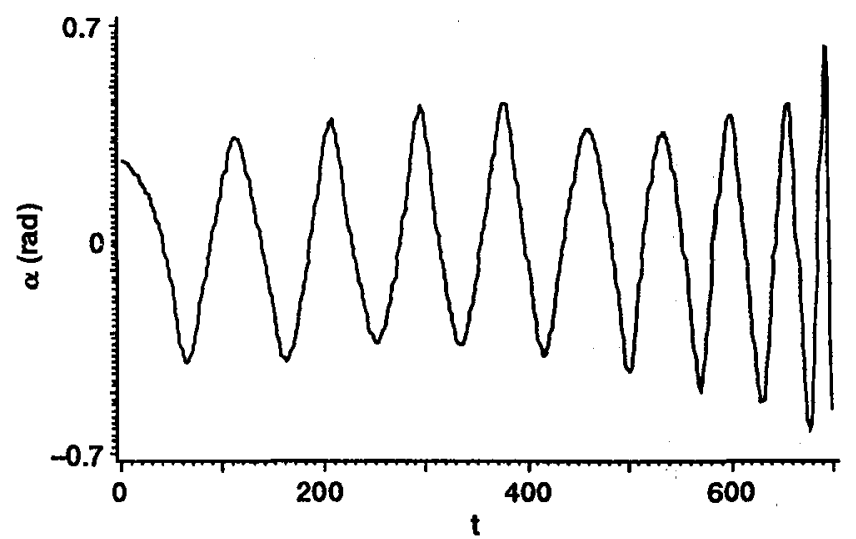

(c) $V^{\star}=7.5$.

Figure 10.-Time response of a two degree-of-freedom solidfluid system using the semi-empirical model over a range of $V^{\star}$ (NACA 0012 airfoil, $M=0.3, R e=4$ million, initial angle of attack $=15^{\circ}$ ).

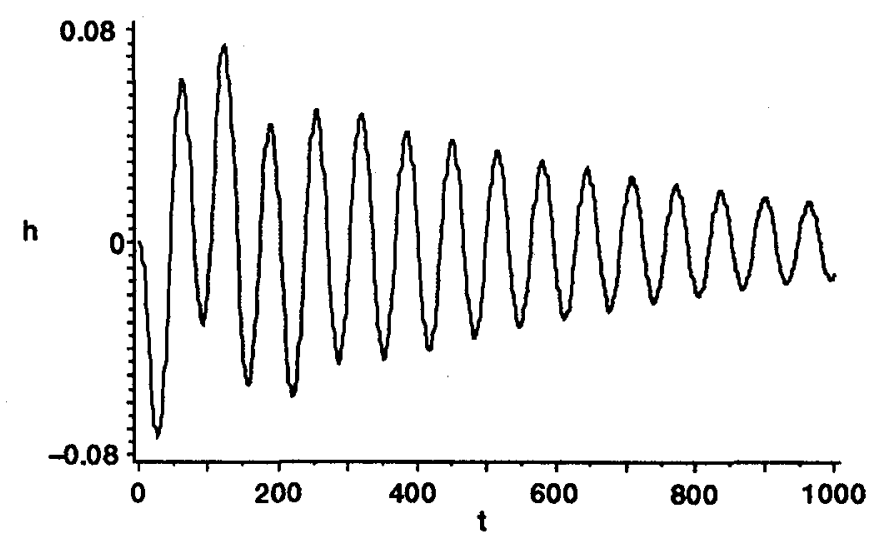

(d) $V^{\star}=5.0$.
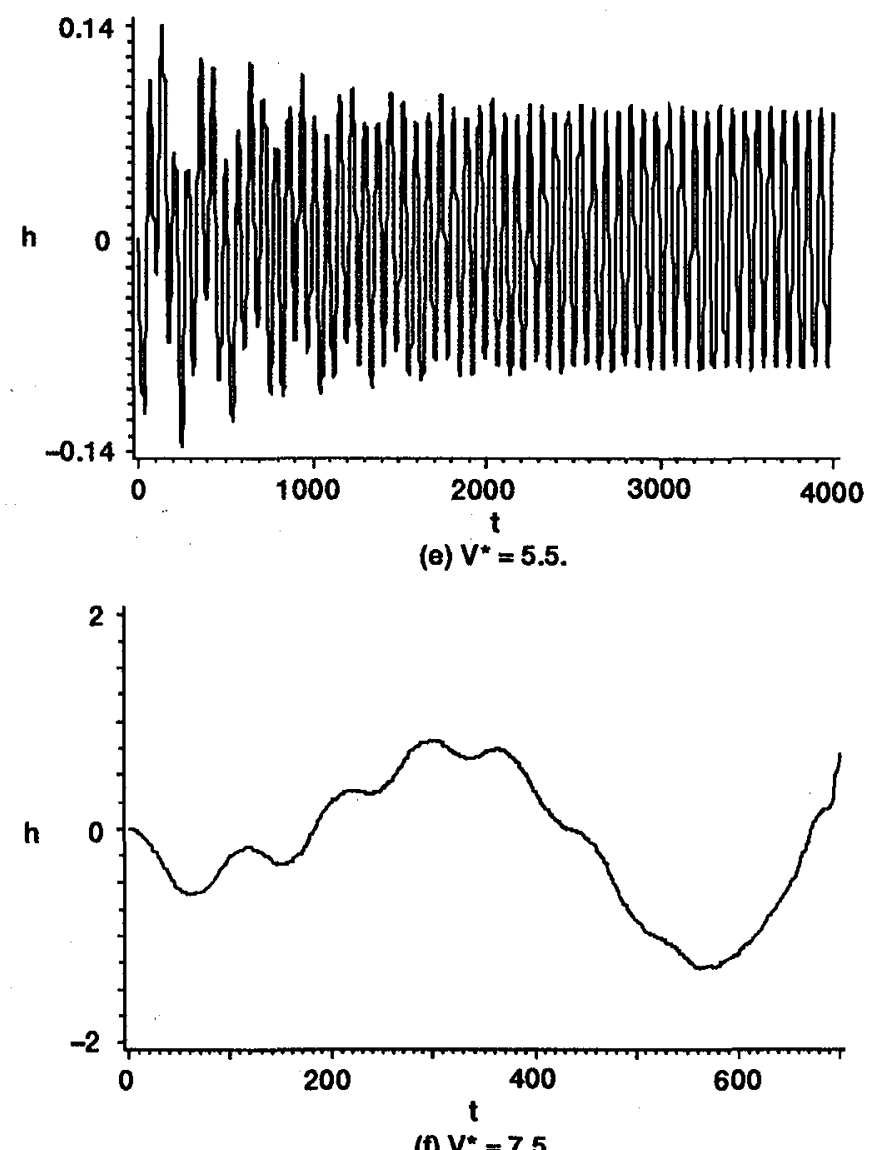

Figure 10.-Concluded. 


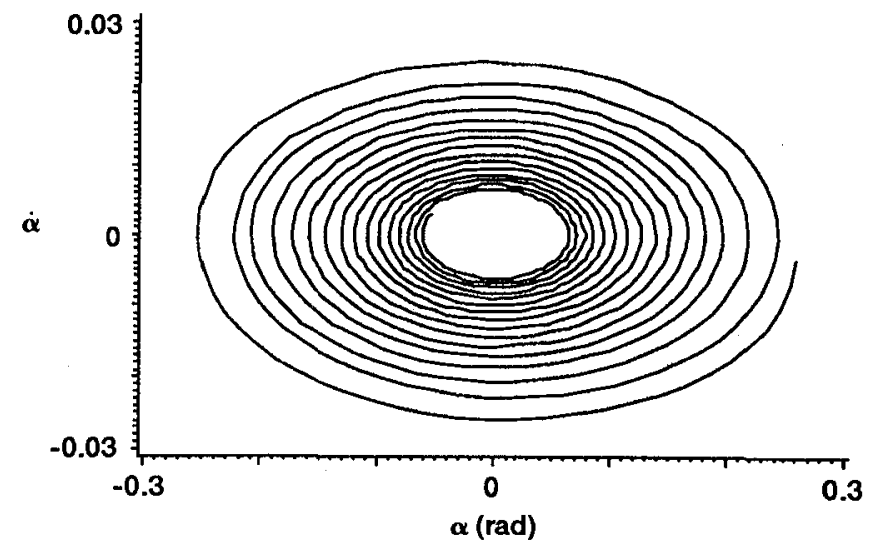

(a) $V^{*}=5.0$

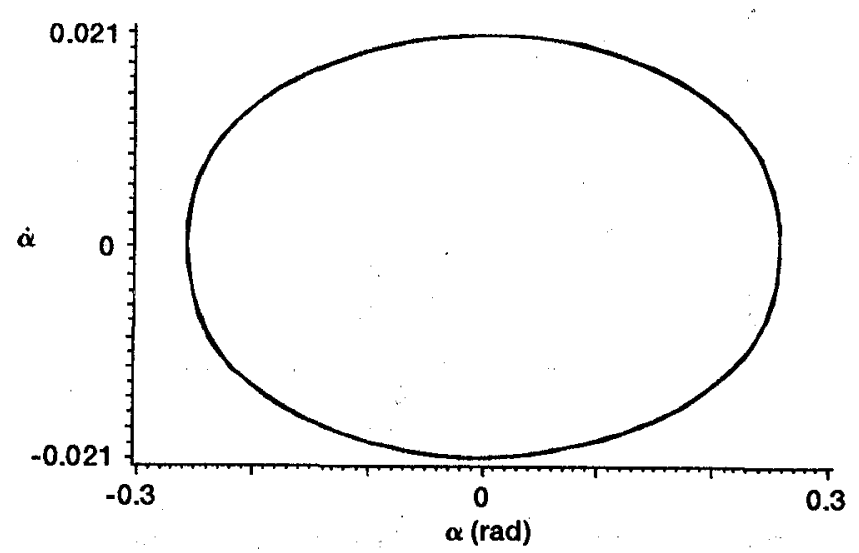

(b) $V^{\star}=5.5$

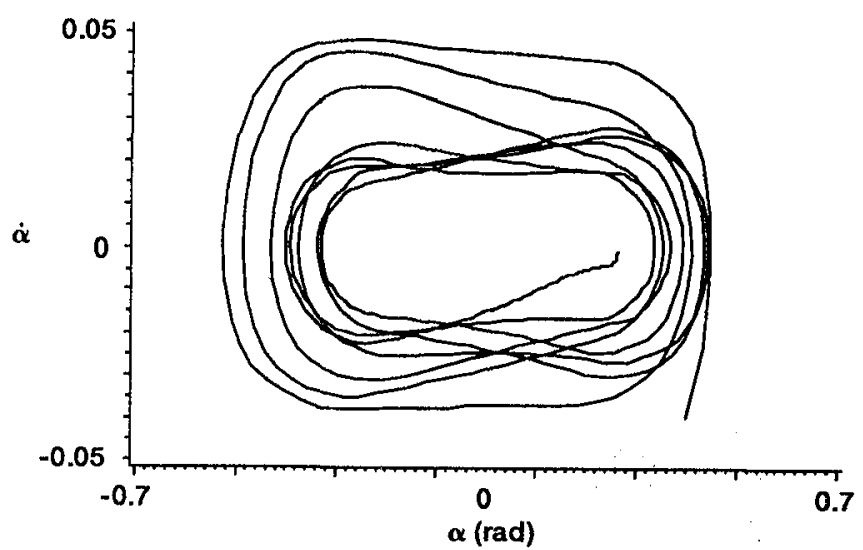

(c) $V^{*}=7.5$.

Figure 11.-Limit cycle behavior in the phase plane for a two degree-of-freedom solid-fluid system using the semi-empirical model over a range of $\mathrm{V}^{*}$ (NACA 0012 airfoil, $\mathrm{M}=0.3, \mathrm{Re}=4$ million, initial angle of attack $=15^{\circ}$ ).

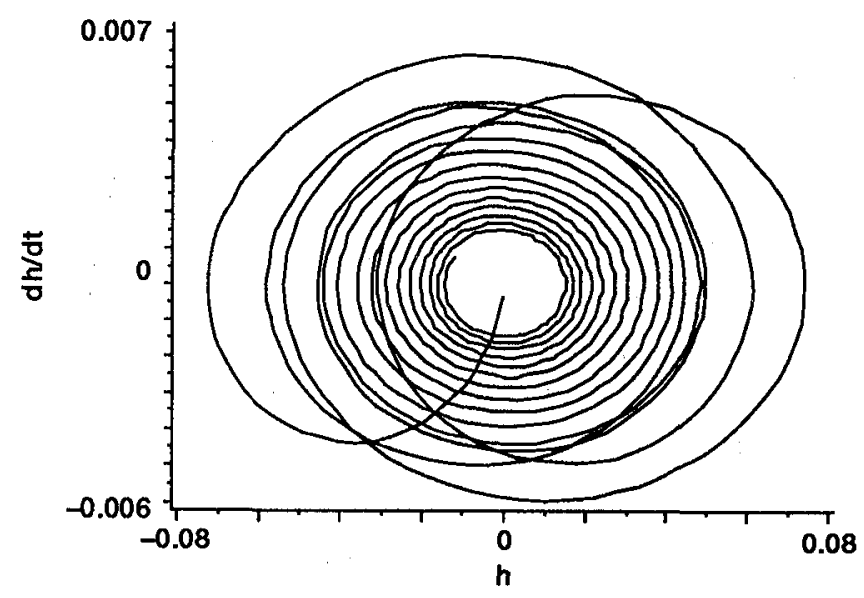

(d) $V^{\star}=5.0$.

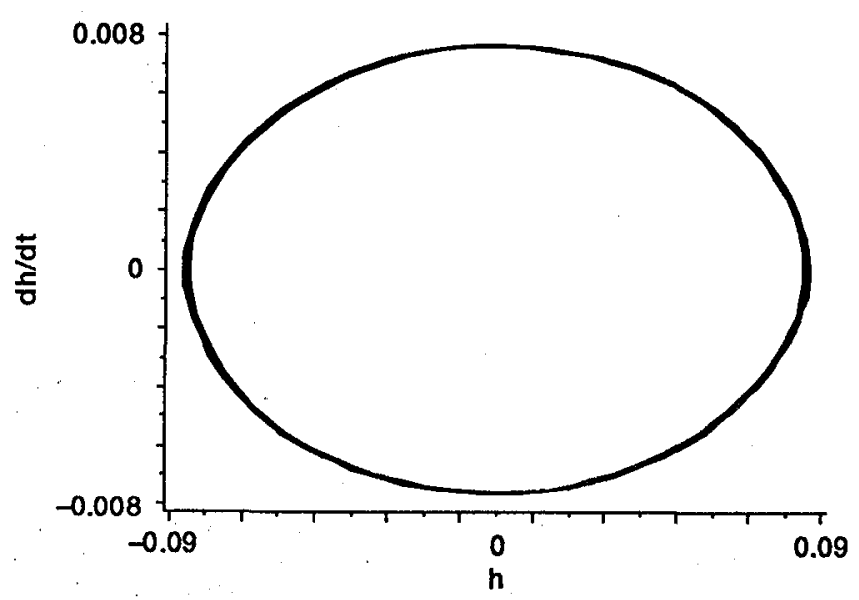

(e) $V^{\star}=5.5$

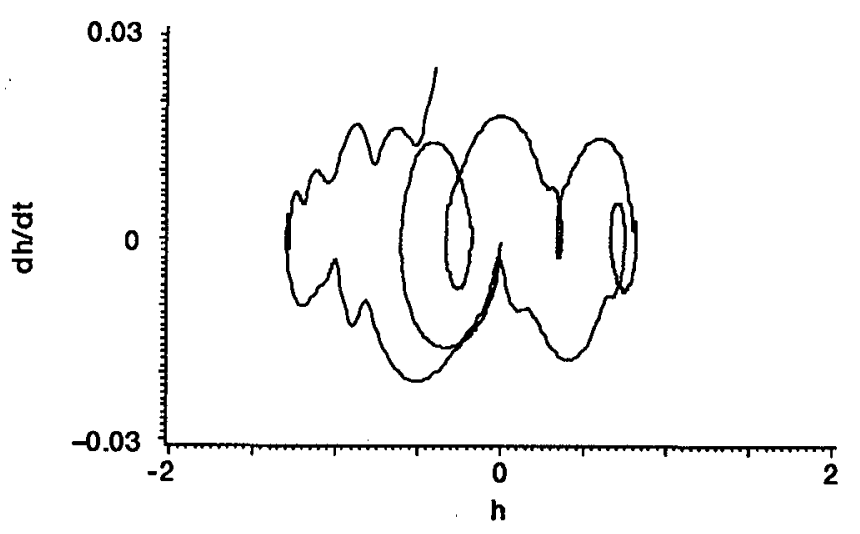

(f) $V^{*}=7.5$.

Figure 11.-Concluded. 


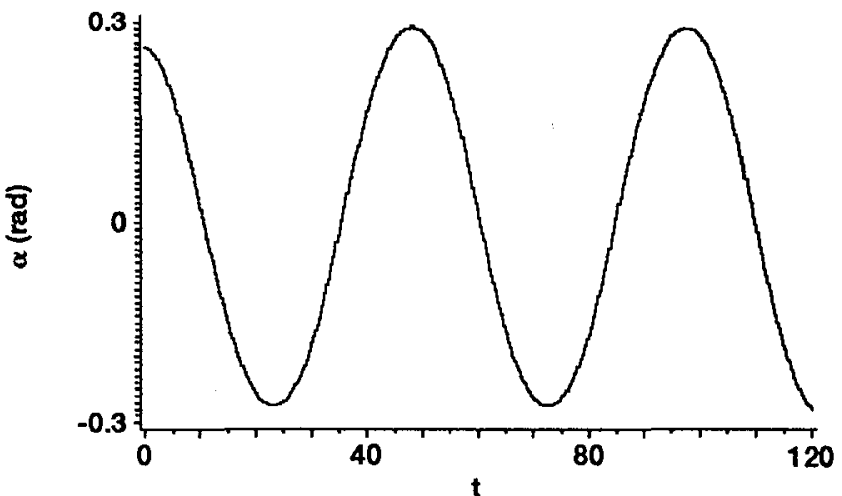

(a) $V^{*}=4.75$

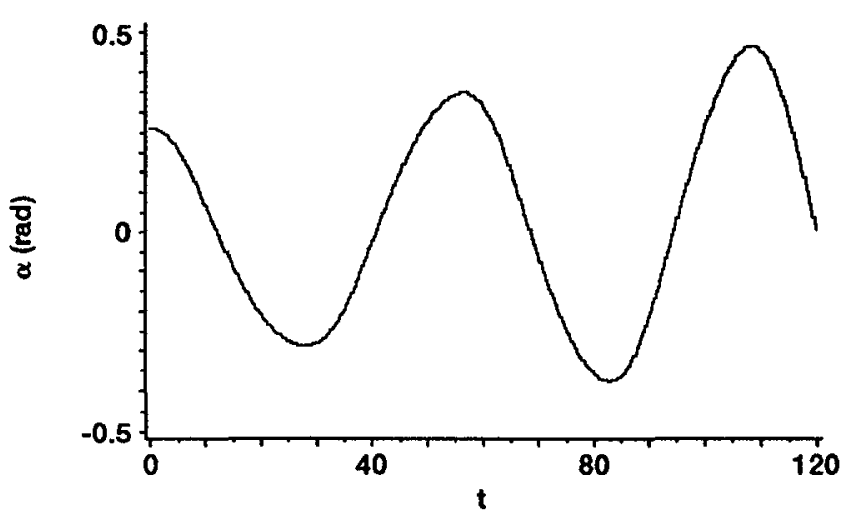

(b) $\mathrm{V}^{*}=5.5$

Figure 12.-Time response of a two degree-of-freedom solid-fluid system using the Navier-Stokes solver over a range of $V^{*}$ (NACA 0012 airfoil, $M=0.3, R e=4$ million, initial angle of attack $=15^{\circ}$ ).

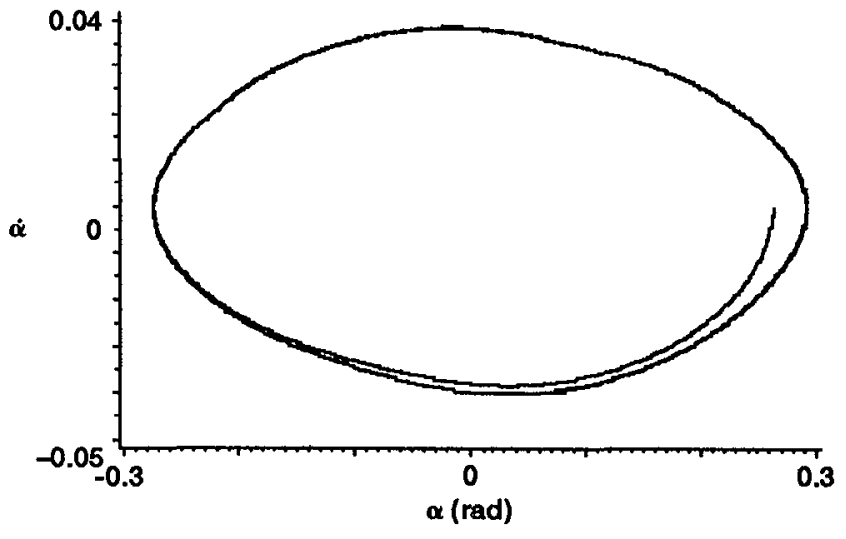

(a) $V^{\star}=4.75$

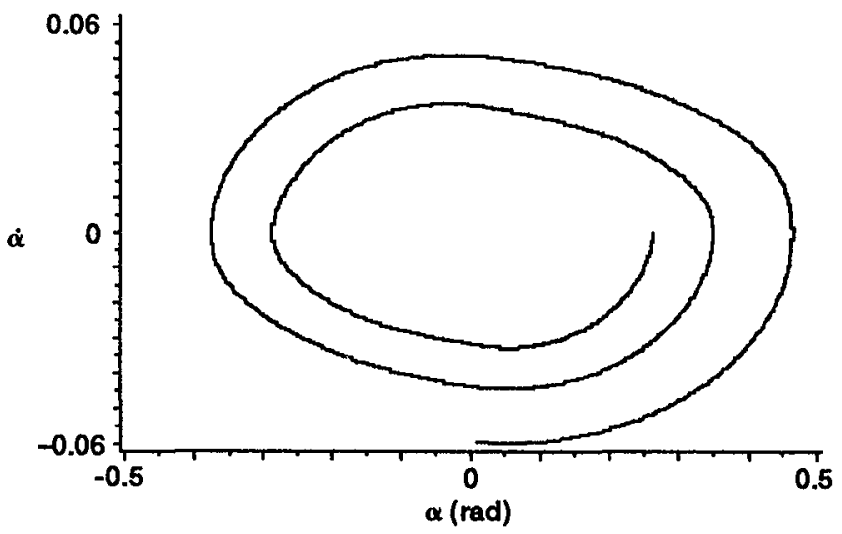

(b) $\mathrm{V}^{\star}=5.5$.

Figure 13.-Limit cycle behavior in the phase plane for a two degree-of-freedom solid-fluid system using the Navier-Stokes solver over a range of $V^{\star}$ (NACA 0012 airfoil, $M=0.3, R e=4$ million, initial angle of attack $=15^{\circ}$ ).

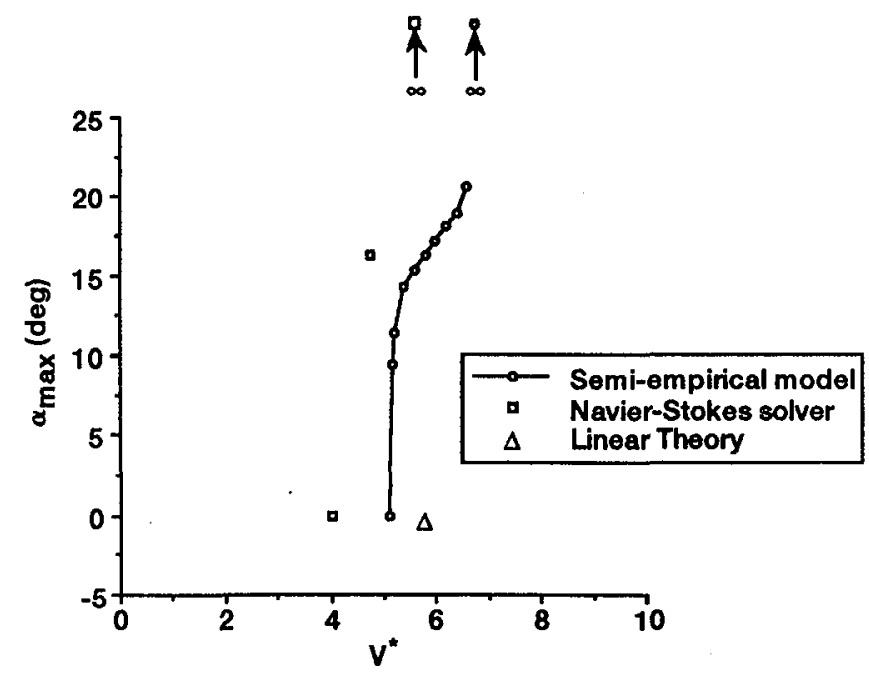

Figure 14. - Maximum limit cycle amplitude as a function of $V^{*}$ (NACA 0012 airfoil, $M=0.3, R \theta=4$ million, initial angle of attack $=15^{\circ}$ ). 
Public reporting burden for this collection of information is estimated to average 1 hour per response, including the time for reviewing instructions, searching existing data sources, gathering and maintaining the data needed, and completing and reviewing the collection of information. Send comments regarding this burden estimate or any other aspect of this collovis Davis Highway, Suite 1204, Arlington, VA 22202-4302, and to the Office of Management and Budget, Paperwork Reduction Project (0704-0188), Washington, DC 20503.
1. AGENCY USE ONLY (Leave blank)
2. REPORT DATE
3. REPORT TYPE AND DATES COVERED
Technical Memorandum

\section{TITLE AND SUBTITLE}

\section{FUNDING NUMBERS}

Semi-Empirical Model for Prediction of Unsteady Forces on an Airfoil With Application to Flutter

\section{AUTHOR(S)}

WU-535-03-10

Aparajit J. Mahajan and Krishna Rao V. Kaza

\section{PERFORMING ORGANIZATION NAME(S) AND ADDRESS(ES)}

National Aeronautics and Space Administration

Lewis Research Center

Cleveland, Ohio 44135-3191

8. PERFORMING ORGANIZATION REPORT NUMBER

National Aeronautics and Space Administration

Washington, D.C. 20546-0001

NASA TM - 105414

\section{SUPPLEMENTARY NOTES}

Aparajit J. Mahajan, University of Toldeo, Toledo, Ohio 43606 and NASA Resident Research Associate at Lewis Research Center. Krishna Rao V. Kaza, (deceased) NASA Lewis Research Center. Responsible person, Aparajit J. Mahajan, (216) 433-6034.

12a. DISTRIBUTION/AVAILABILITY STATEMENT

12b. DISTRIBUTION CODE

Unclassified - Unlimited

Subject Categories 39, 02

\section{ABSTRACT (Maximum 200 words)}

A semi-empirical model is described for predicting unsteady aerodynamic forces on arbitrary airfoils under mildly stalled and unstalled conditions. Aerodynamic forces are modeled using second order ordinary differential equations for lift and moment with airfoil motion as the input. This model is simultaneously integrated with structural dynamics equations to determine flutter characteristics for a two degrees-of-freedom system. Results for a number of cases are presented to demonstrate the suitability of this model to predict flutter. Comparison is made to the flutter characteristics determined by a Navier-Stokes solver and also the classical incompressible potential flow theory.

\section{SUBJECT TERMS}

Aeroelasticity; Flutter; Unsteady aerodynamics

17. SECURITY CLASSIFICATION OF REPORT Unclassified

18. SECURITY CLASSIFICATION
OF THIS PAGE
Unclassified

Unclassified
19. SECURITY CLASSIFICATION OF ABSTRACT Unclassified 